\title{
Electrical Resistivity, Tribological Behaviour of Multiwalled Carbon Nanotubes and Nanoboron Carbide Particles Reinforced Copper Hybrid Composites for Pantograph Application
}

\author{
N. Selvakumar and K. Gangatharan \\ Centre for Nano Science and Technology, Department of Mechanical Engineering, Mepco Schlenk Engineering College, \\ Sivakasi, Virudhunagar, Tamil Nadu 626 005, India
}

Correspondence should be addressed to K. Gangatharan; gangak.87@gmail.com

Received 1 December 2015; Revised 15 March 2016; Accepted 16 March 2016

Academic Editor: Wei Zhou

Copyright (c) 2016 N. Selvakumar and K. Gangatharan. This is an open access article distributed under the Creative Commons Attribution License, which permits unrestricted use, distribution, and reproduction in any medium, provided the original work is properly cited.

\begin{abstract}
This work focuses on the influence and contribution of multiwalled carbon-nanotube (MWCNT)-boron carbide $\left(\mathrm{B}_{4} \mathrm{C}\right)$ to the mechanical and tribological properties of copper matrix composites. Different weight fractions of nano- $\mathrm{B}_{4} \mathrm{C}$-containing fixedweight fractions of MWCNT-reinforced copper composites were prepared using the entrenched cold-press sintering method of powder metallurgy. The wear losses of sintered $\mathrm{Cu}-\mathrm{MWCNT}-\mathrm{B}_{4} \mathrm{C}$ composites were investigated by conducting sliding tests in a pin-on-disc apparatus. The addition of reinforcements showed enhancements in the hardness and wear properties of the composites due to the uniform dispersion of the secondary reinforcement in the copper matrix and the self-lubricating effect of the MWCNTs. The effects of the nanoparticle distribution in the matrix, the worn surface morphology, and the elemental composition of the composites were characterized using high-resolution scanning electron microscopy and X-ray diffraction analysis. The electrical resistivity of the fabricated copper hybrid composite preforms was evaluated using a four-point probe tester. Our results highlight the use of experiential reinforcing limits of $\mathrm{B}_{4} \mathrm{C}$ on the wear and electrical and mechanical behaviour of copper composites.
\end{abstract}

\section{Introduction}

Metal matrix composites are exciting areas of research in which reinforcements of hard ceramic particles are added to improve wear resistance and mechanical performance. Copper is considered as an ideal matrix for composites due to its properties of high electrical and thermal conductivity and is widely used in industrial applications. However, the relatively low hardness and strength and poor wear resistance of copper are crucial factors that limit its extensive application [1-5]. These distinct shortcomings could be avoided by incorporating carbon and nanoceramic particles into the copper matrix, that is, oxides, carbides, and borides used as tribological components, for use of this material in brushes for motors and contact strips for pantographs for railway current collectors. Selection of the correct reinforcement for enhanced physical properties of composites has attracted scientific and technological interest in carbon nanotubes (CNTs), which when paired with a metal matrix offer significant advantages over most existing materials [6-9]. Recently, many researchers have shown that carbon nanotubes (i.e., a three-dimensional carbon material) have higher electrical and thermal conductivities and can be combined with polymer, ceramic, and metal matrices as a strengthening phase using various methods to obtain composites with superior properties [10]. In addition, ceramic particles are preferentially considered as a secondary strengthening phase in the metal matrix to hybridize the composite, which enhances the mechanical properties as well as the wear resistance.

Previous work was carried out by [11-15] fabricated composites by several routes, that is, spraying, hot pressing, hot extrusion, and spark plasma sintering, to obtain excellent mechanical properties. Strengthening of copper composites without the agglomeration of CNTs is the most important 
TABLE 1: Detail of reinforcements.

\begin{tabular}{lccr}
\hline Reinforcement & Grain size & Density $\left(\mathrm{g} / \mathrm{cm}^{3}\right)$ & Morphology \\
\hline MWCNT (as-received) & $5-20(\mathrm{~nm})$ & 2.10 & Stiff and straight \\
$\mathrm{B}_{4} \mathrm{C}$ (as-received) & $44(\mu \mathrm{m})$ & 2.52 & Small flake-like \\
$\mathrm{B}_{4} \mathrm{C}$ (after milling) & $100-200(\mathrm{~nm})$ & 2.52 & Agglomerated sphere \\
\hline
\end{tabular}

challenge. Ravindran et al. [16] found that the particle size and proportion of reinforcement to matrix medium have significant influences on the mechanical properties. Composites reinforced with the addition of nanoceramic particles exhibit better specific strength due to their excellent hardness $[17,18]$. Specimens prepared via powder metallurgy (P/M) are always porous, which decreases the strength of the sintered samples $[19,20]$. However, hard nanoreinforcements can be employed to improve the mechanical properties and fill the porous regions of composite specimens prepared via powder metallurgy methods. Ravindran et al. [21] reported that the wear behaviour of aluminium composites improved by increasing the nanoceramic addition for materials prepared via the powder metallurgy method. A number of research groups have investigated the use of $\mathrm{P} / \mathrm{M}$ for the production of metal matrix nanocomposites incorporated with CNTs [22-24].

However, a copper matrix reinforced with multiwalled carbon nanotubes (MWCNTs) and boron carbide $\left(\mathrm{B}_{4} \mathrm{C}_{p}\right)$ for improvement of wear and mechanical properties prepared using powder metallurgy has not yet been reported. The main objective of this work is to evaluate the combined effect of the higher hardness material (nano $\mathrm{B}_{4} \mathrm{C}$ : 0-2\%) and superconductive material (MWCNTs: $2 \%$ ) as reinforcements in the copper matrix for the improvement of various mechanical and electrical properties for pantograph application. In the current work, an attempt is carried out to determine the wear rate, electrical resistivity, and mechanical properties of composites prepared using the powder metallurgy method.

\section{Experimental Procedure}

2.1. Materials. Pure electrolytic copper powder with $99.7 \%$ purity and an average particle size of less than $10 \mu \mathrm{m}$ supplied by $\mathrm{M} / \mathrm{s}$. Metal Powder Company Limited, India, was selected as the matrix material. MWCNTs with an average tube diameter of $5-20 \mathrm{~nm}$ and length of $5 \mu \mathrm{m}$ (Sigma Aldrich private limited, India) and ball-milled $\mathrm{B}_{4} \mathrm{C}_{p}$ with particle sizes near $100 \mathrm{~nm}$ (which have an effect on the reduction in wear and increase in mechanical properties) were selected as the reinforcement elements for the experimental study. Details of the nanoreinforcements are provided in Table 1. Examination of the powder morphology of the matrix and nanoreinforcements was carried out using SEM, and images are shown in Figures 1(a)-1(c). Figures 1(a) and 1(b) show that the as-received copper particles are irregular in shape, and the $\mathrm{B}_{4} \mathrm{C}$ particles are characterized by a small flake-like morphology. Figure 1(c) shows an SEM image of MWCNTs with a stiffer and straighter tube-like structure. A Zetasizer (Model: Nano ZS90 Malvern, UK) was used to determine the exact size of the reinforcement particles, and Figure 1(d) shows the average particle size of MWCNT powders. The FTIR spectra of the as-received $\mathrm{B}_{4} \mathrm{C}$ particles show absorption peaks at $1554.90 \mathrm{~cm}^{-1}$ and $1076.31 \mathrm{~cm}^{-1}$, as shown in Figure 1(e). Figure 1(f) displays the FT-IR spectra of as-received MWCNT, including the characteristic absorption peaks at $1506 \mathrm{~cm}^{-1}$ and $1643.41 \mathrm{~cm}^{-1}$ that confirm the spectra of pure MWCNTs [25].

2.2. Fabrication of Composites and Characterization. In this experiment, high-energy ball milling and cold compaction followed by sintering processes were used to develop the $\mathrm{Cu}-$ MWCNT- $\mathrm{B}_{4} \mathrm{C}$ composites.

2.2.1. Mixing. Figures 2(a)-2(b) display SEM micrographs of the ball-milled nano- $\mathrm{B}_{4} \mathrm{C}$ particles and the average particle size of the $\mathrm{B}_{4} \mathrm{C}$ powder after milling for $25 \mathrm{~h}$. The most suitable technique for uniform dispersion of secondary particles (MWCNT and $\mathrm{B}_{4} \mathrm{C}$ ) throughout the matrix $(\mathrm{Cu})$ was attained using the mechanical alloying process [1]. For fabrication of the composites, amounts of MWCNTs and $\mathrm{B}_{4} \mathrm{C}$ particles were measured to attain weight percentages of $0.5 \%, 1.0 \%, 1.5 \%$, and $2.0 \%$ and were mixed with fine-grained copper powder in a high-energy planetary ball mill (Fritsch, Germany) containing tungsten carbide balls of $10 \mathrm{~mm}$ diameter (with a ball-to-powder weight ratio of $20: 1$ ) for $2 \mathrm{~h}$. A copper matrix strengthened by the addition of two hard nanoreinforcements $\left(\mathrm{B}_{4} \mathrm{C}\right.$ and MWCNTs) is known as a hybrid composite. During ball milling of powders, argon gas and toluene were used as process control agents to prevent oxidation and contamination. The mixed powders were collected from each sample and were characterized for morphology using Scanning Electron Microscope (SEM). The even distribution of reinforcements is clearly observed in the SEM image. Figure 2(a) shows that the milled nano- $\mathrm{B}_{4} \mathrm{C}$ particles appear as agglomerated sphere-like structures. Figure 2(b) shows that the average particle size of the nano $\mathrm{B}_{4} \mathrm{C}_{p}$ was approximately $100 \mathrm{~nm}$. Figures 2(c)-2(g) show micrographs of composite powders with different weight $\%$ of $\mathrm{B}_{4} \mathrm{C}$ particles and a constant weight $\%$ of MWCNTs. As shown in all micrographs, the MWCNTs are evenly dispersed in the copper matrix. The fine distribution of both reinforcements in the copper matrix resulted from the choice of an appropriate mixing time $(2 \mathrm{~h})$ and method of mixing (planetary ball milling). Figures $2(\mathrm{~d})-2(\mathrm{~g})$ reveal not only the homogenous distribution of the CNT in a copper matrix but also the distribution of nano- $\mathrm{B}_{4} \mathrm{C}$ particles. After the milling process, the hard reinforcements were inserted into the soft copper matrix as confirmed through X-ray diffraction (XRD) characterization.

2.2.2. Compaction and Sintering. Next, the mixed composite powders were compacted using a punch-and-die set assembly 


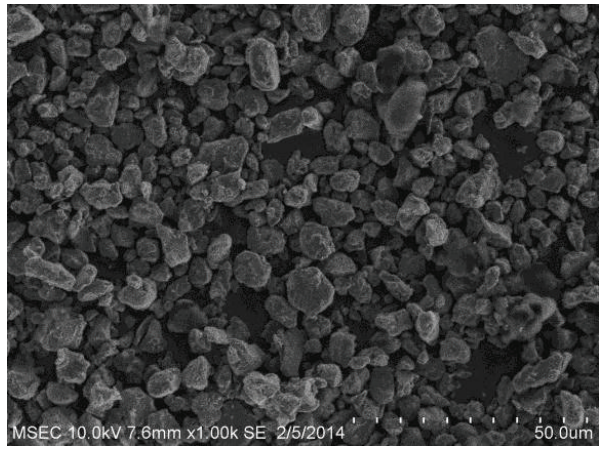

(a)

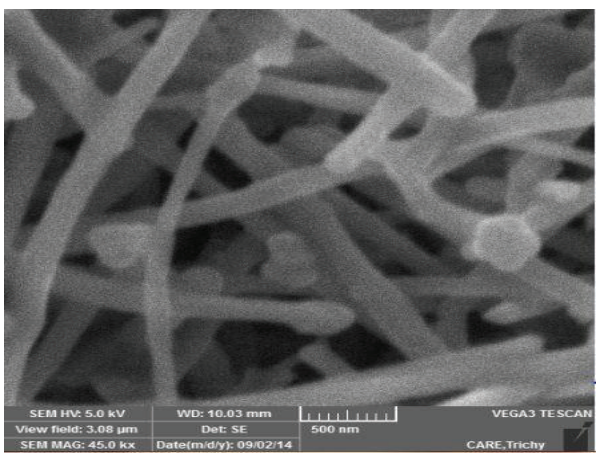

(c)

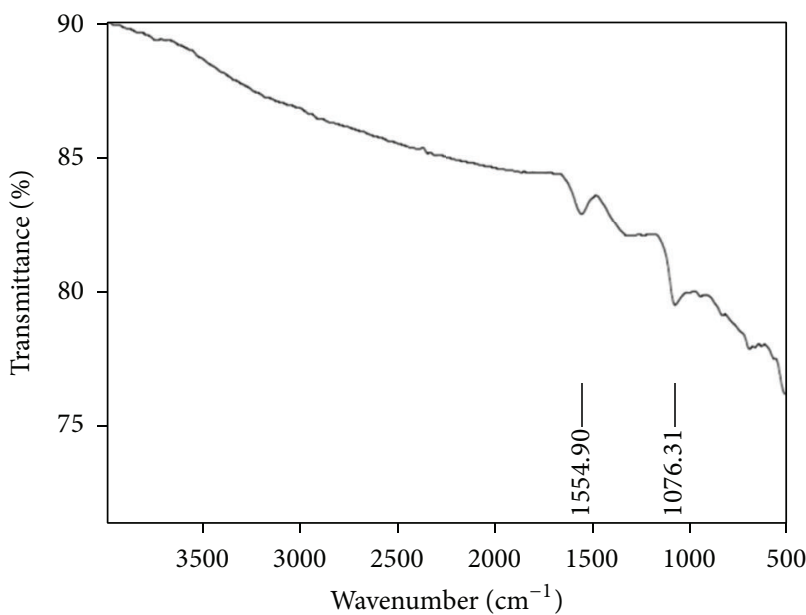

(e)

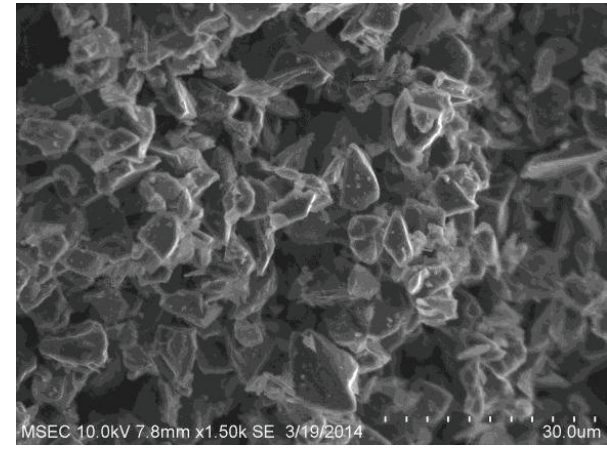

(b)

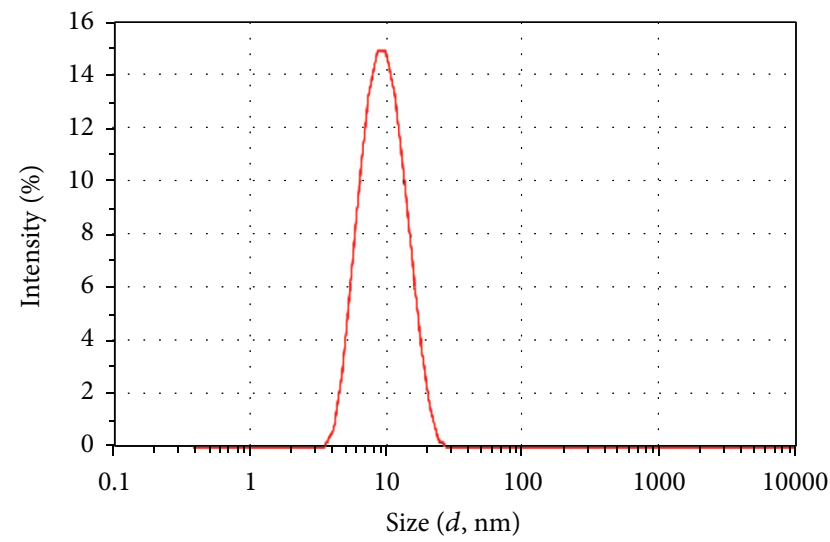

(d)

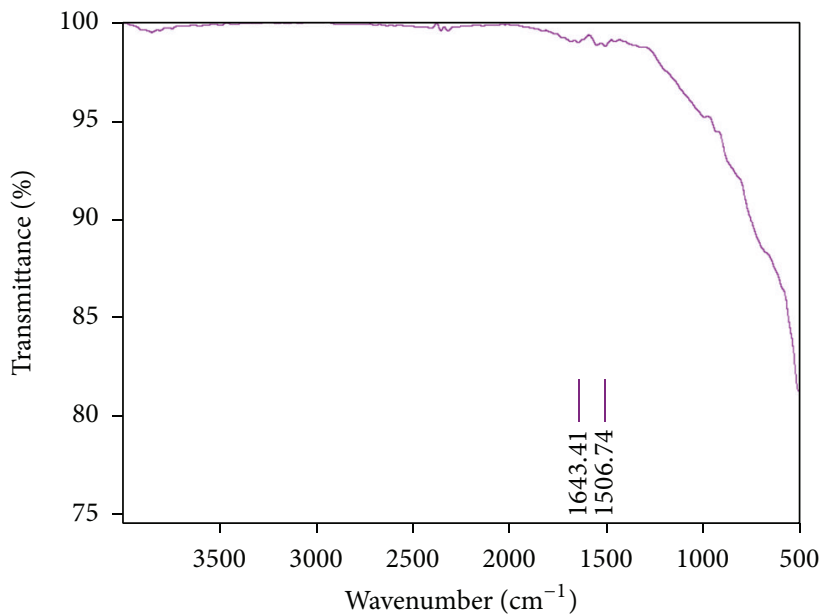

(f)

FIGURE 1: (a-d) SEM micrographs of powders: (a) as received Cu powders, (b) as received $\mathrm{B}_{4} \mathrm{C}$, (c) MWCNTs, (d) average particle size of the MWCNTs, (e) FTIR spectra for $\mathrm{B}_{4} \mathrm{C}$, and (f) FTIR spectra for MWCNTs.

on an electrically operated compression testing machine $(1000 \mathrm{kN})$, as shown in Figure 3. For easy ejection of green compacts, molybdenum disulphide was used as the die wall and punch lubricant. Cylindrical green compacts of $10 \mathrm{~mm}$ diameter and $25 \mathrm{~mm}$ length were prepared. The ram speed was applied gradually at a rate of $1 \mathrm{~mm} / \mathrm{min}$ to achieve excellent hardness values. The compacted composite specimens were sintered in an argon atmosphere at $850^{\circ} \mathrm{C}$ in a muffle furnace for $1 \mathrm{~h}$ and allowed to cool to room temperature in the furnace [26]. The sintering temperature of the composite specimens was optimized using the trial-and-error method. At the end of the processes, MWCNTs and nano- $\mathrm{B}_{4} \mathrm{C}$ reinforced copper hybrid composite preforms were obtained without oxidation and contamination. The schematic view of 


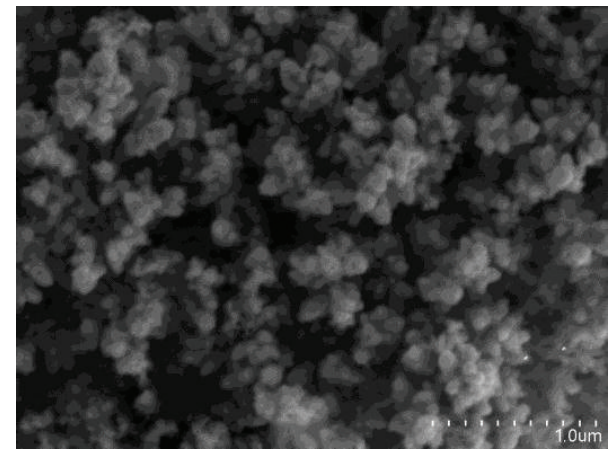

(a)

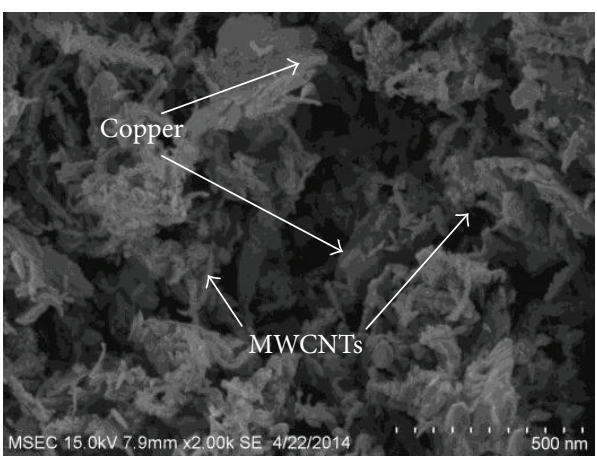

(c)

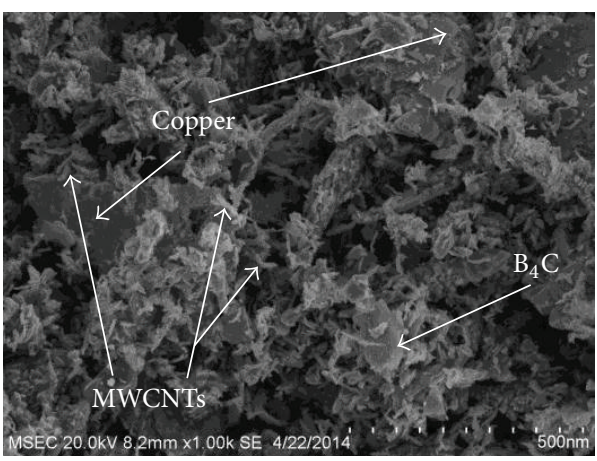

(e)

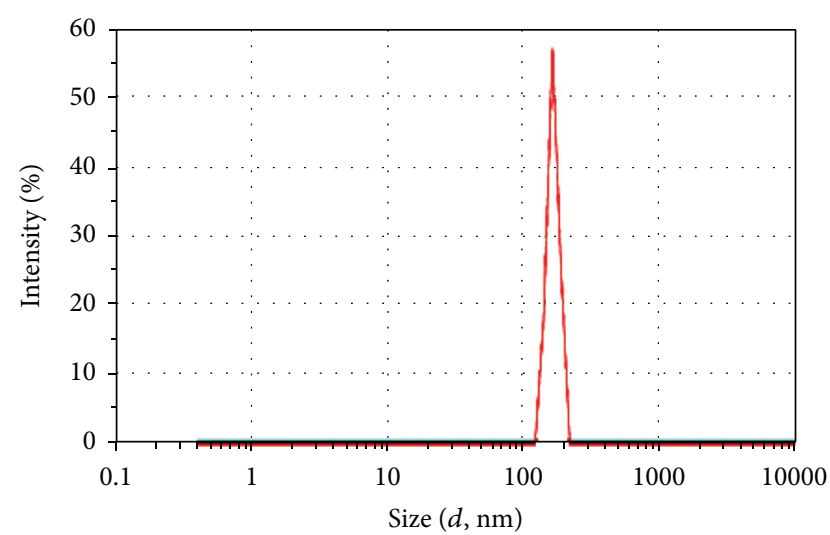

(b)

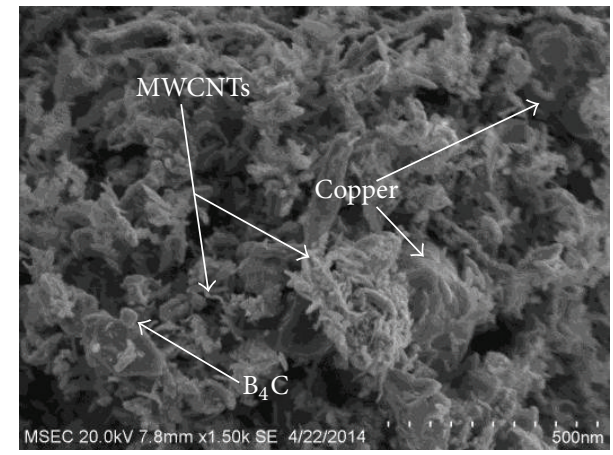

(d)

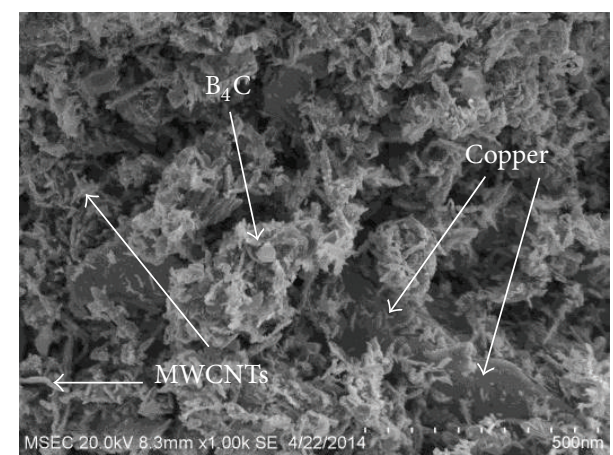

(f)

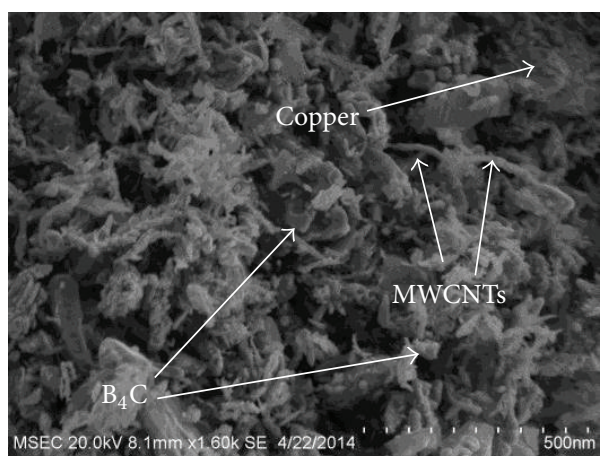

(g)

Figure 2: SEM micrographs of (a) nano sized $\mathrm{B}_{4} \mathrm{C}$ particles after $25 \mathrm{~h}$ of milling, (b) average particle size of $\mathrm{B}_{4} \mathrm{C}$ after $25 \mathrm{~h}$ of milling, (c) $\mathrm{Cu}-2 \mathrm{MWCNT}$, (d) Cu-2MWCNT-0.5B $\mathrm{B}_{4} \mathrm{C}$, (e) Cu-2MWCNT-1.0B $\mathrm{B}_{4} \mathrm{C}$, (f) $\mathrm{Cu}-2 \mathrm{MWCNT}-1.5 \mathrm{~B}_{4} \mathrm{C}$, and (g) $\mathrm{Cu}-2 \mathrm{MWCNT}-2.0 \mathrm{~B}_{4} \mathrm{C}$. 


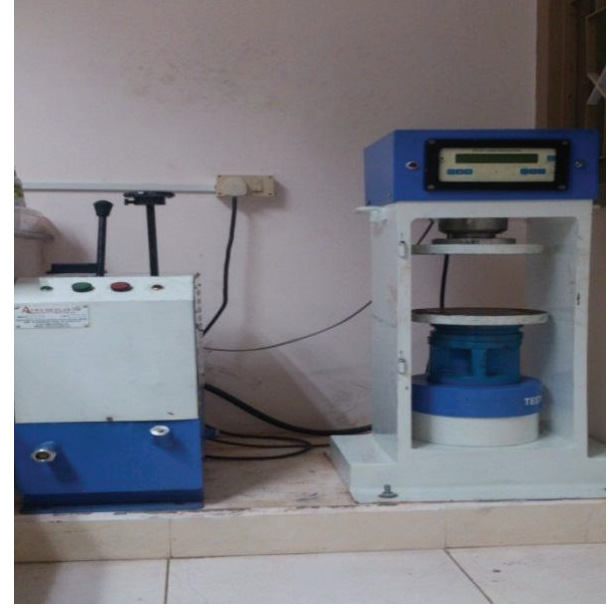

FIGURE 3: Compression testing machine.

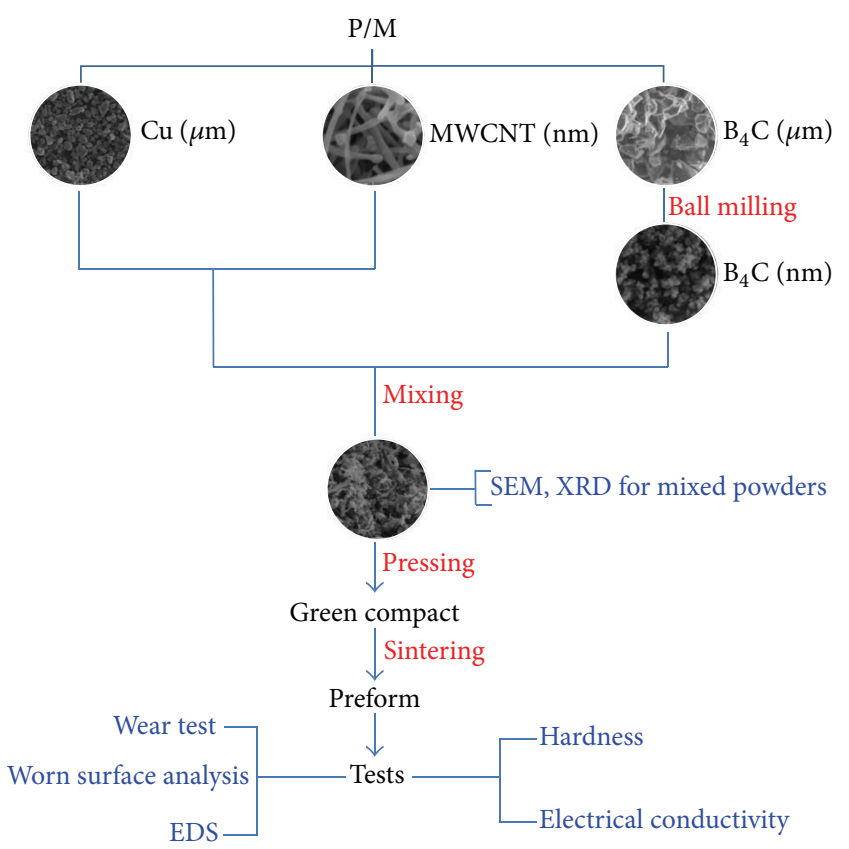

Figure 4: Process flow diagram.

the process flow diagram of this experimentation is shown in Figure 4. The microstructure of the composite specimens after sintering is shown in Figure 5.

2.3. Density and Porosity. The actual sintered density of the copper hybrid composite specimens was determined using the Archimedes principle, and the results are shown in Figure 6 . The samples were weighed using an electronic balance (Make: Sartorius, Model: BS 224S) with an accuracy of $0.1 \mathrm{mg}$. The theoretical density of the copper-based composite specimen was calculated using the rule of mixture [20]. The relative density of the composite specimens was calculated from the ratio of the actual density to the theoretical density. The details of the copper hybrid composites are given in Table 2.
The residual porosities of copper-based hybrid composites were at minimum $1-8 \%$.

2.4. Vickers Hardness. The hardness values of the copper composites were determined using the Vickers hardness method with an applied load of $10 \mathrm{~kg}$. The copper composite specimens were fabricated with a diameter of $10 \mathrm{~mm}$ and a height of $10 \mathrm{~mm}$. Prior to testing, each sample was cleaned using acetone and metallographically polished with abrasive paper of grades 600,800 , and 1000 and with alumina paste as a final step.

2.5. Electrical Resistivity. The well-known four-point probe tester (SES instruments Pvt. Ltd., Roorkee, India) was used to determine the electrical resistivity in this experiment [26]. In general, electrical resistivity (specific electrical resistance) quantifies how strongly a given material opposes the flow of electrons. The matrix metal chosen for this study (copper) has good electrical conductivity compared with those of the any other metals. The electrical resistivity test was conducted in a dynamic nitrogen atmosphere with a constant current $(I=$ $0.5 \mathrm{~A}$ ) and varying temperature. The diameter of the samples was $10 \mathrm{~mm}$, and the length was $25 \mathrm{~mm}$. The composite specimens were polished using a fine-grade emery sheet to improve contact before testing. A thermocouple was used to vary the temperature during the test, and measurements of voltage $(\mathrm{V})$ were collected using DC current.

2.6. Wear Testing. Friction and wear tests for the prepared copper composite specimens were conducted in air at room temperature in a pin-on-disc tribometer (Ducom, Bangalore) as per the ASTM G99-05 standard [27]. Prismatic composite pins of $10 \mathrm{~mm}$ diameter with an axis normal to the sliding direction were used as the test specimens. The composite pin was loaded against the disc by a dead-weight loading system. The specimens and disc were washed in acetone to ensure that the wear tests were carried out under nominally dry sliding conditions. An electronic balance (Make: Shimadzu, Model: AX 200) with a precision of $0.1 \mathrm{mg}$ was used to measure the weight of the specimens before and after each test. The specific wear rate and friction coefficient were calculated from the weight loss of the composite specimen and frictional torque measured by the pin-on-disc test machine during the experiment, respectively. The diameter of the sliding track on the disc surface was held constant at $100 \mathrm{~mm}$ with a specified rotational speed $(500 \mathrm{rpm})$ and sliding velocity $(3.14 \mathrm{~m} / \mathrm{s})$. An EN 31 steel disc with $60 \mathrm{HRC}$ was used as the sliding disc of the pin during the wear test. A schematic diagram of the pin-on-disc apparatus is shown in Figure 7. The weight loss obtained from each wear test was converted into volume loss using the actual density of the corresponding composite. The specific wear rate is calculated by [1]

$$
\begin{gathered}
\text { Specific wear rate }\left(\mathrm{mm}^{3} / \mathrm{N}-\mathrm{m}\right) \\
=\frac{\text { Volume loss }}{(\text { Load } \times \text { Sliding distance })} .
\end{gathered}
$$


TABLE 2: Detail of the test specimens.

\begin{tabular}{lccc}
\hline S. number & Composition $($ wt. $\%)$ & Theoretical density $\left(\mathrm{g} / \mathrm{cm}^{3}\right)$ & Actual preform density $\left(\mathrm{g} / \mathrm{cm}^{3}\right)$ \\
\hline 1 & $\mathrm{Cu} / 2$ wt.\% of MWCNT & 8.7862 & 8.1564 \\
2 & $\mathrm{Cu} / 2$ wt.\% of MWCNT $/ 0.5$ wt. $\%$ of $\mathrm{B}_{4} \mathrm{C}$ & 8.7540 & 8.1289 \\
3 & $\mathrm{Cu} / 2$ wt.\% of MWCNT $/ 1.0$ wt. $\%$ of $\mathrm{B}_{4} \mathrm{C}$ & 8.7218 & 8.0944 \\
4 & $\mathrm{Cu} / 2$ wt.\% of MWCNT $/ 1.5$ wt. $\%$ of $\mathrm{B}_{4} \mathrm{C}$ & 8.6896 & 8.0745 \\
5 & $\mathrm{Cu} / 2$ wt.\% of MWCNT $/ 2.0$ wt. $\%$ of $\mathrm{B}_{4} \mathrm{C}$ & 8.6574 & 8.0712 \\
\hline
\end{tabular}

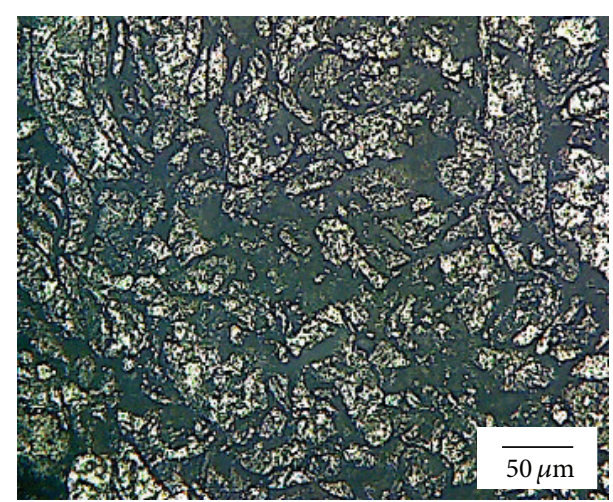

(a)

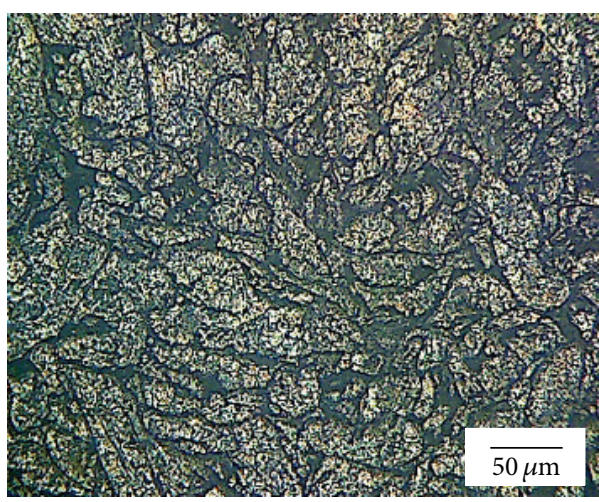

(c)

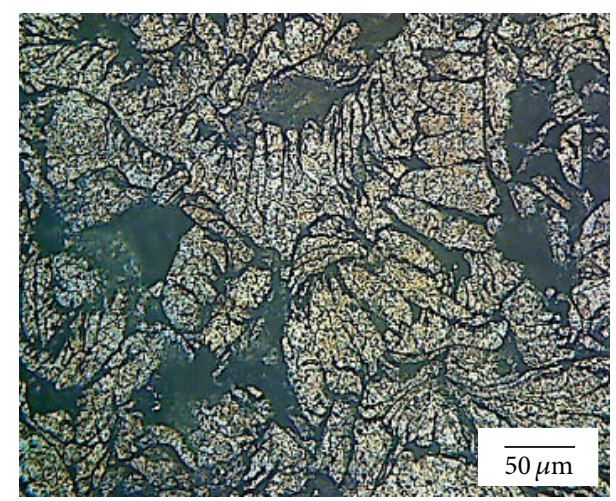

(b)

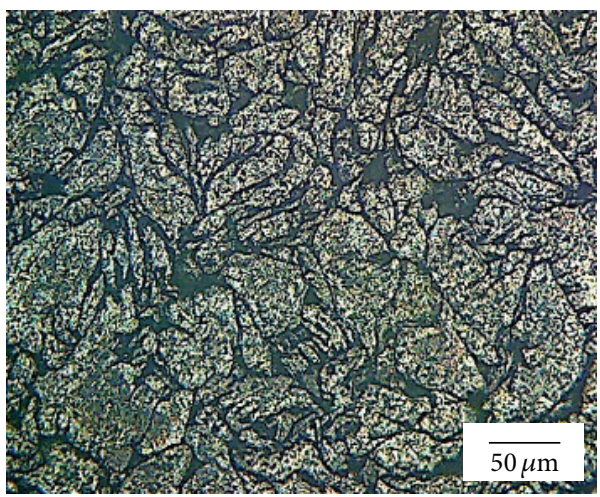

(d)

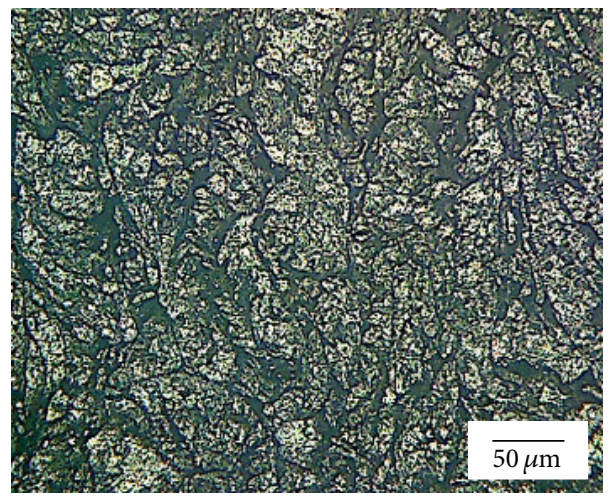

(e)

Figure 5: Optical micrographs of sintered specimens: (a) Cu-2MWCNT, (b) $\mathrm{Cu}-2 \mathrm{MWCNT}-0.5 \mathrm{~B}_{4} \mathrm{C}$, (c) $\mathrm{Cu}-2 \mathrm{MWCNT}-1.0 \mathrm{~B}_{4} \mathrm{C},(\mathrm{d}) \mathrm{Cu}-$ $2 \mathrm{MWCNT}-1.5 \mathrm{~B}_{4} \mathrm{C}$, and (e) $\mathrm{Cu}-2 \mathrm{MWCNT}-2.0 \mathrm{~B}_{4} \mathrm{C}$. 


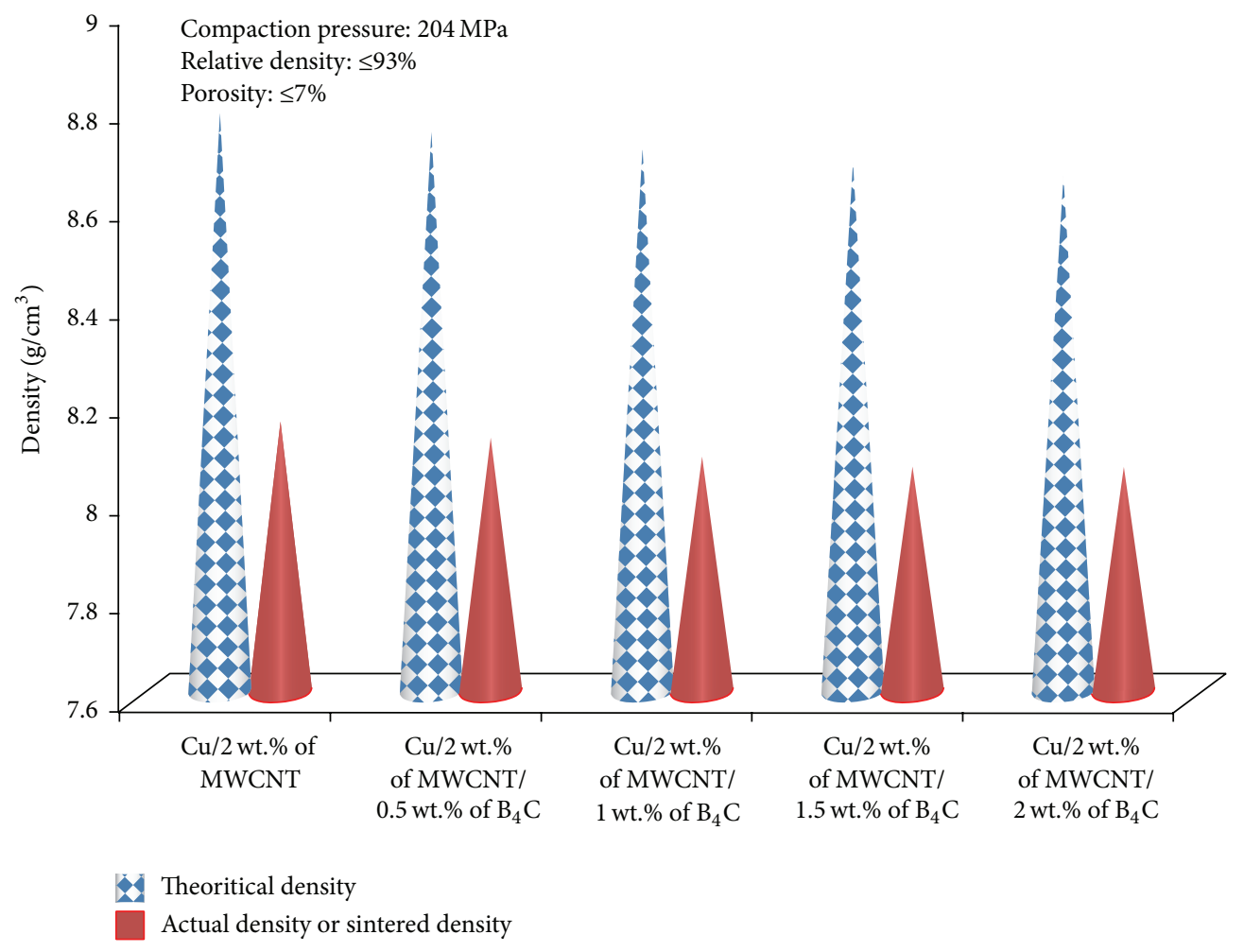

FIGURE 6: Density values of the sintered preforms.

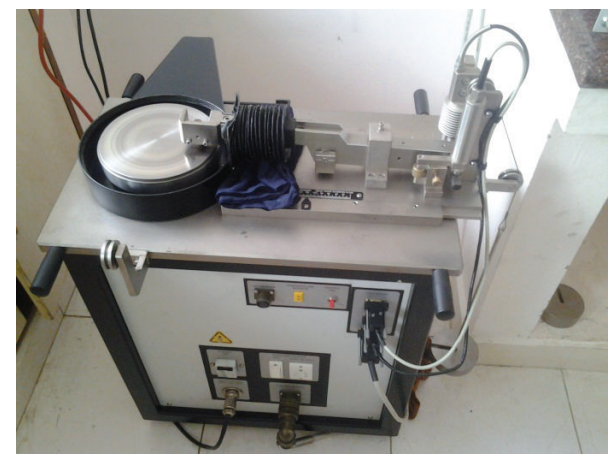

FIGURE 7: Schematic view of the pin-on-disc wear testing machine.

In the current work, two series of experiments were performed:

(i) The effect of applied load: five copper-based preforms in Table 2 were chosen. The applied load ranged from $5 \mathrm{~N}$ to $20 \mathrm{~N}$.

(ii) The effect of sliding distance: the sliding distance ranged from $500 \mathrm{~m}$ to $1500 \mathrm{~m}$. The $\mathrm{B}_{4} \mathrm{C}$ particle weight fraction varied from $0 \%$ to $2 \%$ in the hybrid composites containing a fixed $2 \mathrm{wt}$.\% MWCNT.

2.7. Observations of Worn Surfaces and Wear Debris. To explore the wear mechanisms of the monolithic copper hybrid composites, the worn surface regions of wear samples tested at different loads and the wear debris were observed using scanning electron microscopy (SEM).

\section{Results and Discussion}

3.1. XRD Characterization. Powder X-ray diffraction (XRD) patterns of the copper composites reinforced with MWCNT and nano- $\mathrm{B}_{4} \mathrm{C}$ particles were collected on the ball-milled powder samples. The diffraction peak values of the ultrafine mixed composite powders were recorded at room temperature over the angular range $(2 \theta)$ of $10^{\circ}$ to $80^{\circ}$ with a step size of $0.02^{\circ}$ and a $3 \mathrm{~s}$ step interval. The $\mathrm{X}$-rays used to diffract the samples were generated by a $\mathrm{Cu}-\mathrm{K} \alpha$ radiation source $(\lambda=1.54060 \AA)$. As there is no impurity peak rather than the characteristic peaks of copper, the purity of the matrix material is confirmed. Average crystalline size is calculated by using the Debye Scherer formula as shown in (2) [28]. The average crystalline size of the copper is calculated by considering broadening of all the peaks from Figure 8 and the value is found to be $78.74286 \mathrm{~nm}$. Average crystalline size calculated from (2) for the milled nano $\mathrm{B}_{4} \mathrm{C}$ is found to be $11.1881 \mathrm{~nm}$. Very sharp peaks of the reflections are responsible for this reduced crystalline size:

$$
D=\frac{n \lambda}{\beta \cos \theta},
$$

where $n$ is equal to $0.9, \lambda$ is wavelength of $\mathrm{X}$-ray's used, $1.54060 \AA, \beta$ is full width at half maximum, and $\theta$ is angle of reflection. 


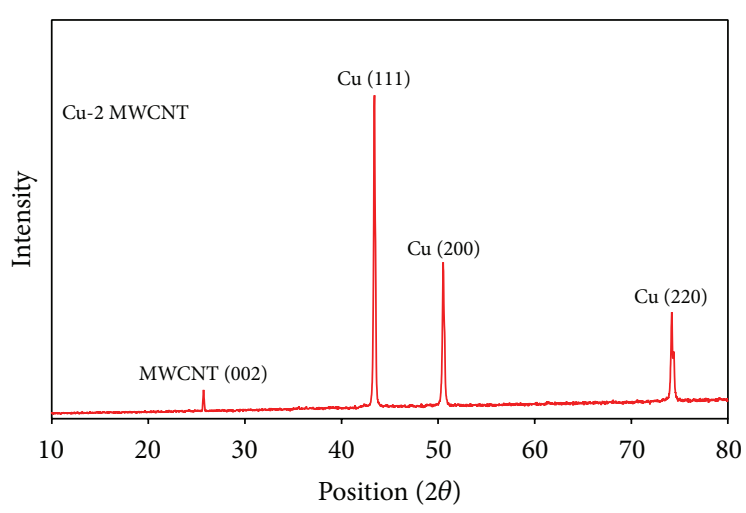

(a)

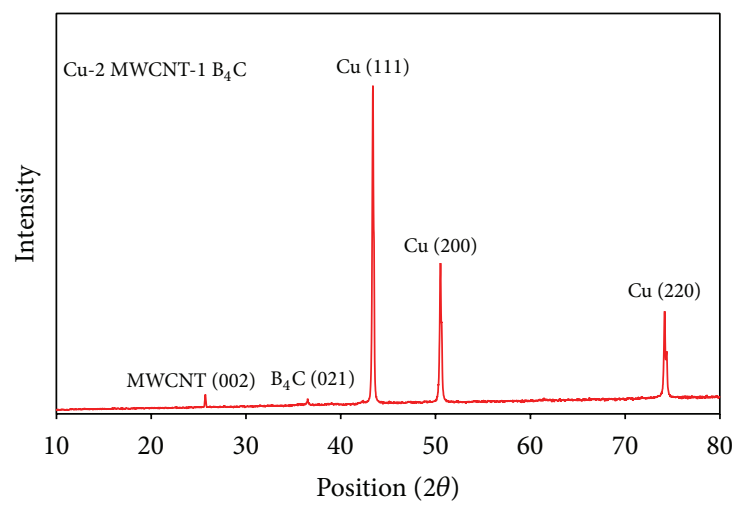

(c)

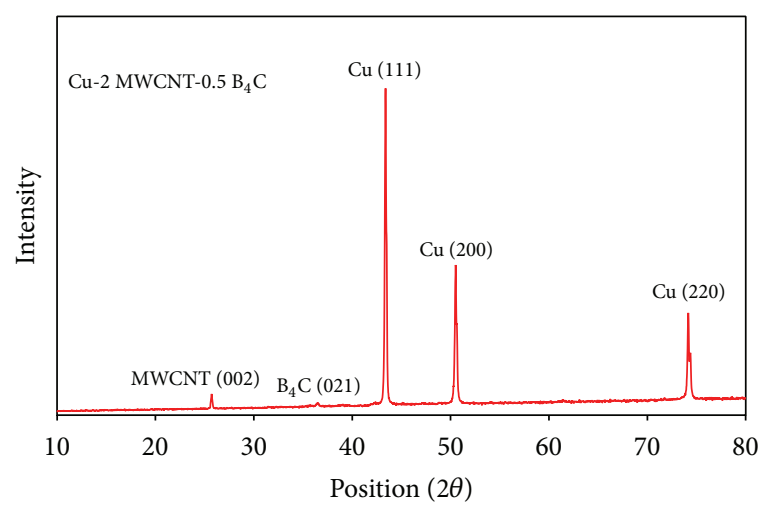

(b)

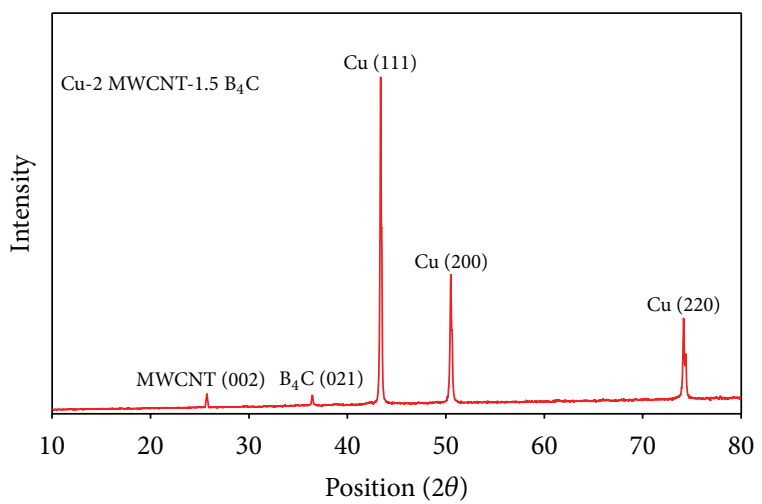

(d)

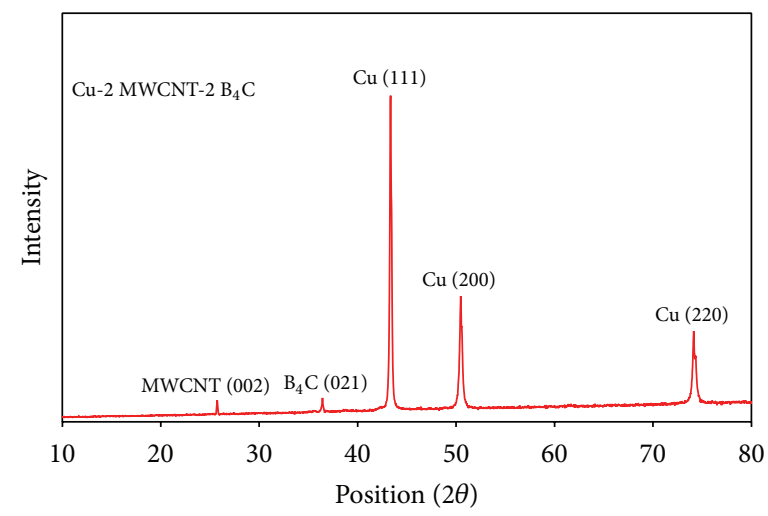

(e)

FIGURE 8: XRD results for the mixed composite powders: (a) $\mathrm{Cu}-2 \mathrm{MWCNT}$, (b) $\mathrm{Cu}-2 \mathrm{MWCNT}-0.5 \mathrm{~B}_{4} \mathrm{C},(\mathrm{c}) \mathrm{Cu}-2 \mathrm{MWCNT}-1.0 \mathrm{~B}_{4} \mathrm{C},(\mathrm{d})$ $\mathrm{Cu}-2 \mathrm{MWCNT}-1.5 \mathrm{~B}_{4} \mathrm{C}$, and (e) $\mathrm{Cu}-2 \mathrm{MWCNT}-2.0 \mathrm{~B}_{4} \mathrm{C}$.

Powder X-ray diffraction (XRD) patterns of the copper composites reinforced with MWCNT and nano- $\mathrm{B}_{4} \mathrm{C}$ particles were collected on the ball-milled powder samples. The diffraction peak values of the ultrafine mixed composite powders were recorded at room temperature over the angular range $(2 \theta)$ of $10^{\circ}$ to $80^{\circ}$ with a step size of $0.02^{\circ}$ and a $3 \mathrm{~s}$ step interval. Figures $8(\mathrm{a})-8(\mathrm{e})$ display the XRD spectra of the prepared copper composite powders. The presence and distribution of copper, $\mathrm{B}_{4} \mathrm{C}$, and MWCNTs in the powder composite mixture were confirmed via $\mathrm{XRD}$ characterization. The intensity peaks of carbon-rich $\mathrm{B}_{4} \mathrm{Cs}$ and MWCNTs are slightly similar to each other and were found to be weak in comparison with copper, which consists predominantly of $\mathrm{Cu}$ peaks. Furthermore, the intensities of $\mathrm{B}_{4} \mathrm{C}$ peak were prominently increased with the increasing weight percentage of $\mathrm{B}_{4} \mathrm{C}$. The MWCNT intensity showed relatively low values due to the reinforcement level of $2 \mathrm{wt} . \%$. The diffraction peaks of $\mathrm{Cu}$ were found at (1 111$),\left(\begin{array}{lll}2 & 0 & 0\end{array}\right)$, and $\left(\begin{array}{lll}2 & 2 & 0\end{array}\right)$, corresponding to the file name (JCPDS card number 892838). The crystal plane ( $\left.\begin{array}{lll}0 & 0 & 2\end{array}\right)$ for MWCNT is located between $25.6313^{\circ}$ and $25.8693^{\circ}$, corresponding to the file name (JCPDS card number 75-1621). In the case of $B_{4} C$, the peak ( $\left.\begin{array}{ll}0 & 2\end{array}\right)$ is located near $36.4263^{\circ}$ of the $2 \theta$ range (JCPDS card number 00-035-0798). 


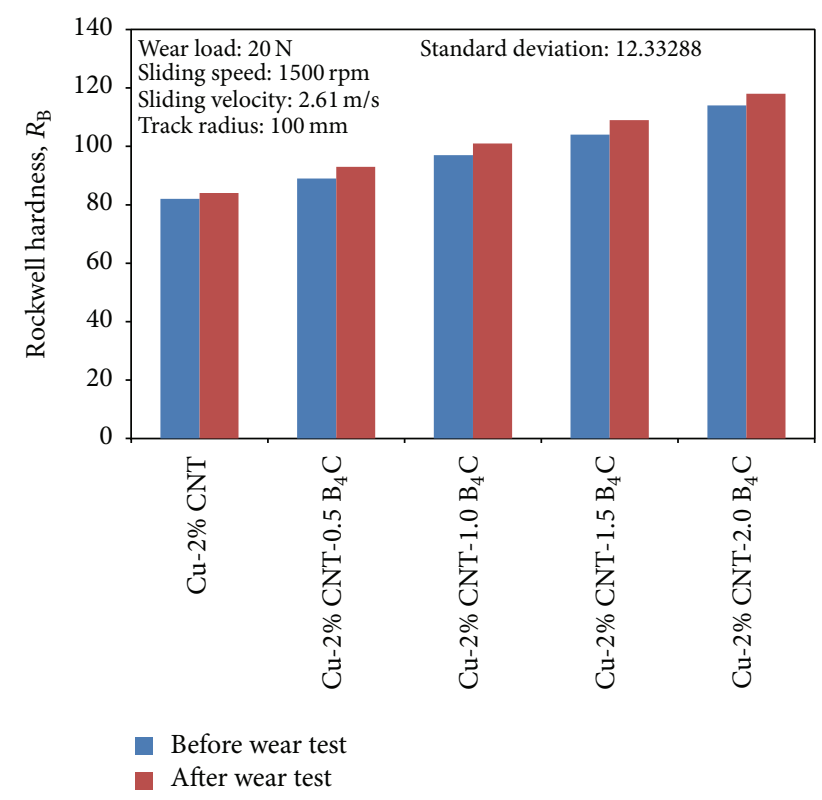

Figure 9: Hardness values of $\mathrm{Cu}-2$ wt.\% of MWCNT-B ${ }_{4} \mathrm{C}$ composites.

3.2. Hardness Analysis. The hardness measurements were collected at five different locations on each sample to obtain an average value of hardness on the polished surface. Figure 9 shows a comparison of hardness values on the prepared composites with varying weight $\%$ of $\mathrm{B}_{4} \mathrm{C}$. The results confirm that the Vickers hardness (HV) of the specimen increases with an increase in weight percentage of $\mathrm{B}_{4} \mathrm{C}$ up to 2 wt.\%. The increase in hardness of the hybrid composite is attributed to the following reasons: (i) the high hardness of the $\mathrm{B}_{4} \mathrm{C}$ reinforcement (ceramic) particles [26] and (ii) the uniform distribution of carbon nanotubes. The hardness of the composite specimens was increased after wear testing due to the formation of hard asperities $\left(\mathrm{B}_{4} \mathrm{C}\right)$ on the surface of the specimens [5]. The mechanism behind this hardness result is dispersion strengthening. The Orowan mechanism (dispersion strengthening) plays a crucial role on the strengthening of the composites, particularly when the reinforcement size is less than $100 \mathrm{~nm}$ [29].

3.3. Electrical Resistivity. Figure 10 describes the electrical resistivity results for pure copper and copper hybrid composites tested under various temperature conditions. To calculate the resistivity and verify the obtained resistance, the ratio between voltage and current was taken into account. The experimentally obtained electrical resistivity values of a pure copper specimen with varying temperature are $1.842 \times$ $10^{-8} \Omega-\mathrm{m}(R T), 1.91 \times 10^{-8} \Omega-\mathrm{m}\left(50^{\circ} \mathrm{C}\right)$, and $1.97 \times 10^{-8} \Omega$ $\mathrm{m}\left(70^{\circ} \mathrm{C}\right)$. A significant increase in the electrical resistivity of the pure copper specimen associated with a drop in the resistance $R$ was observed by the four-point probe tester and compared with the reference value of $1.7241 \times 10^{-8} \Omega$ $\mathrm{m}$ [9]. The results show that the temperature and weight $\%$ play a crucial role in determining the electrical resistivity of copper hybrid composites. The secondary reinforcement
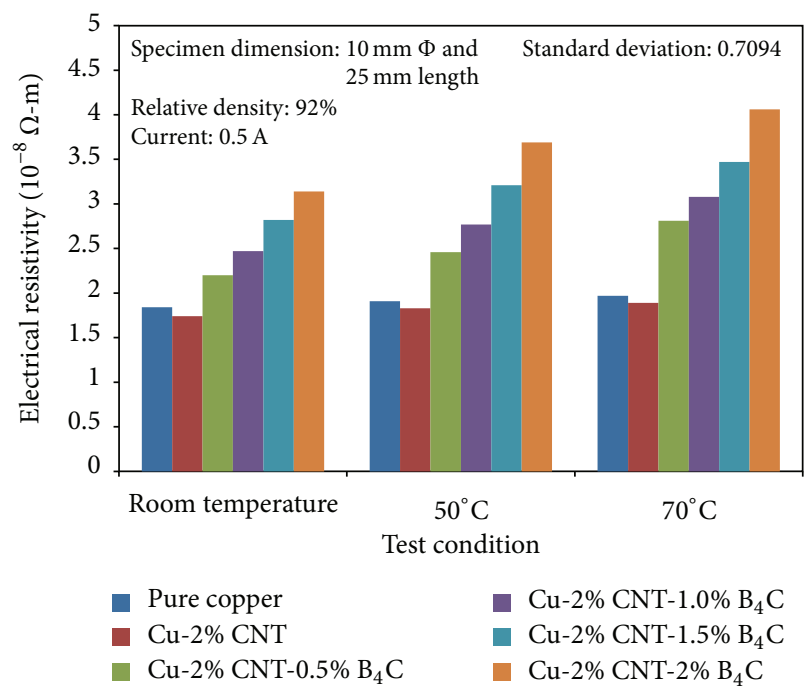

FIGURE 10: Electrical resistivity of copper matrix composites.

revealed the highest oxidation resistance among the three tested materials [30]. However, the temperature is not the only factor that controls the resistivity; the pores in the specimen, which act as barriers and slightly oppose the flow of electrons, can be considered an important factor as well. The resistivity values of a 2 wt.\% MWCNT-reinforced copper specimen are $1.74 \times 10^{-8} \Omega-\mathrm{m}(R T), 1.83 \times 10^{-8} \Omega$ $\mathrm{m}\left(50^{\circ} \mathrm{C}\right)$, and $1.89 \times 10^{-8} \Omega-\mathrm{m}\left(70^{\circ} \mathrm{C}\right)$ lower compared with the value of the pure copper specimen. Resistivity is an intrinsic feature that specifies the electrical properties of a material and depends on electron-phonon scattering near room temperature. The reason that resistivity of $\mathrm{Cu}$ increases with increasing temperature (Figure 10) is that the number of imperfections in the atomic lattice structure increases with temperature and this hampers electron movement. In our case, imperfection such as interstitial defects (pores) is observed due to the relative density of $93 \%$. Additionally, above absolute zero, even the lattice atoms participate in the interference of directional electron movement as they are not always found at their ideal lattice sites. Thermal energy causes the atoms to vibrate about their equilibrium positions. At any moment in time many individual lattice atoms will be away from their perfect lattice sites and this interferes with electron movement causes for increased resistivity.

Another approach to reducing resistivity of $\mathrm{Cu}$ involves the addition of MWCNT, which can enhance the conducting mechanism of the metal and thereby significantly reduce the resistivity. But resistivity of $\mathrm{B}_{4} \mathrm{C}\left(0.5 \Omega \cdot \mathrm{cm}^{-1}\right)$ [30] is generally higher than that of pure metals and increases with impurity contamination. As the $\mathrm{B}_{4} \mathrm{C}$ concentration increases, the hopping rate decreases and reduces the probability of acceleration of the charge carriers. The consequent mobility is decreased and thereby the resistivity increases. This dispersion in resistivity with frequency can be explained by Koop's theory [31]. The value of resistivity is dependent on the band energy and temperature; however, authors assumed that the addition 


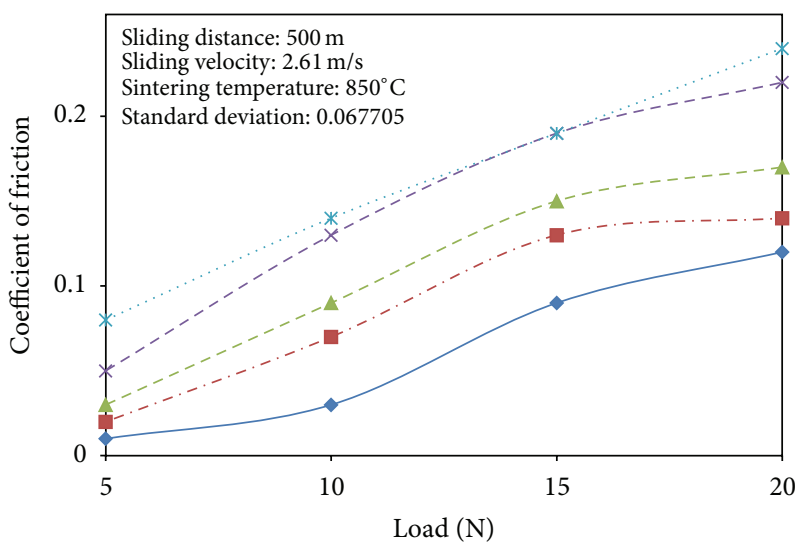

$\bullet-\mathrm{Cu}-2 \% \mathrm{CNT}+2 \% \mathrm{~B}_{4} \mathrm{C} \quad-*-\mathrm{Cu}-2 \% \mathrm{CNT}+0.5 \% \mathrm{~B}_{4} \mathrm{C}$

- $-\mathrm{Cu}-2 \% \mathrm{CNT}+1.5 \% \mathrm{~B}_{4} \mathrm{C} \quad \ldots * \cdot \mathrm{Cu}-2 \% \mathrm{CNT}$

- - $\mathrm{Cu}-2 \% \mathrm{CNT}+1 \% \mathrm{~B}_{4} \mathrm{C}$

(a)

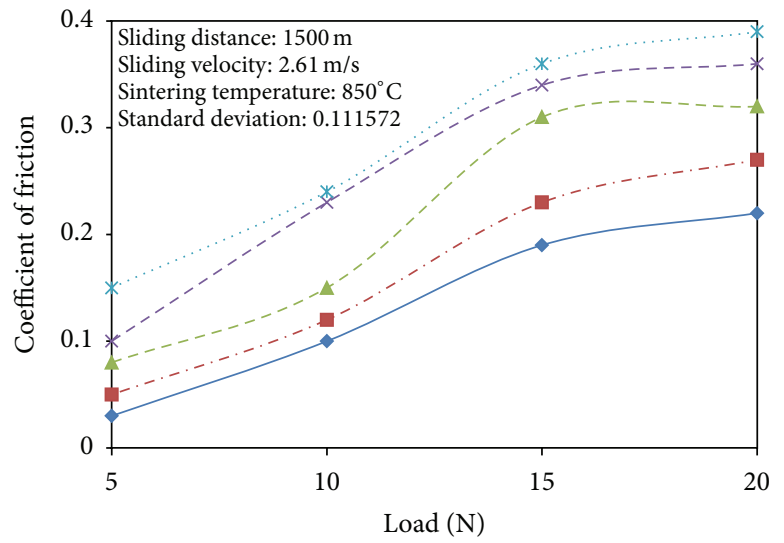

$\rightarrow \mathrm{Cu}-2 \% \mathrm{CNT}+2 \% \mathrm{~B}_{4} \mathrm{C} \quad-*-\mathrm{Cu}-2 \% \mathrm{CNT}+0.5 \% \mathrm{~B}_{4} \mathrm{C}$

- $\mathrm{Cu}-2 \% \mathrm{CNT}+1.5 \% \mathrm{~B}_{4} \mathrm{C} \quad \ldots * \mathrm{Cu}-2 \% \mathrm{CNT}$

$-\mathrm{Cu}-2 \% \mathrm{CNT}+1 \% \mathrm{~B}_{4} \mathrm{C}$

(c)

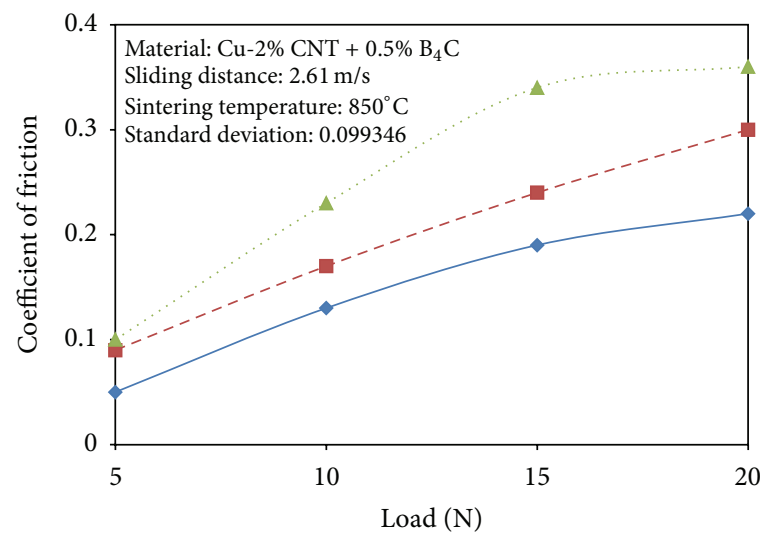

Sliding distance:

$\rightarrow 500 \mathrm{~m}$

$-1000 \mathrm{~m}$

-. $1500 \mathrm{~m}$

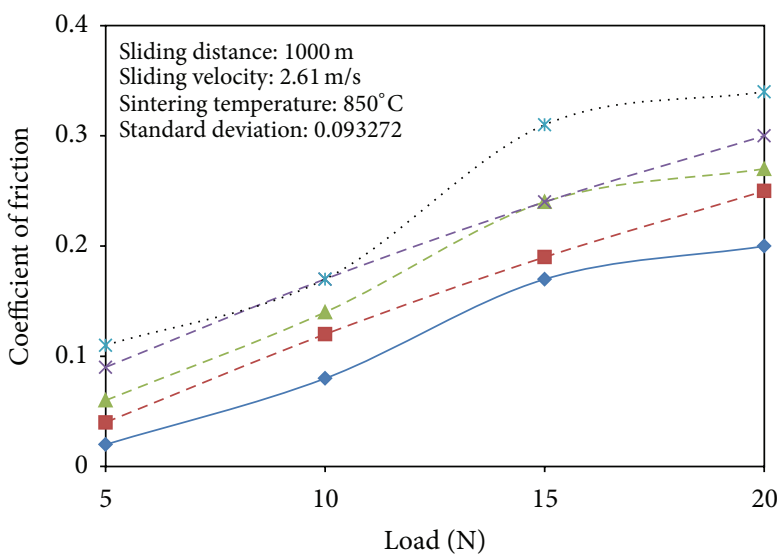

$\rightarrow \mathrm{Cu}-2 \% \mathrm{CNT}+2 \% \mathrm{~B}_{4} \mathrm{C} \quad-*-\mathrm{Cu}-2 \% \mathrm{CNT}+0.5 \% \mathrm{~B}_{4} \mathrm{C}$

- - $\mathrm{Cu}-2 \% \mathrm{CNT}+1.5 \% \mathrm{~B}_{4} \mathrm{C} \quad \ldots * \cdot \mathrm{Cu}-2 \% \mathrm{CNT}$

$-\mathrm{Cu}-2 \% \mathrm{CNT}+1 \% \mathrm{~B}_{4} \mathrm{C}$

(b)

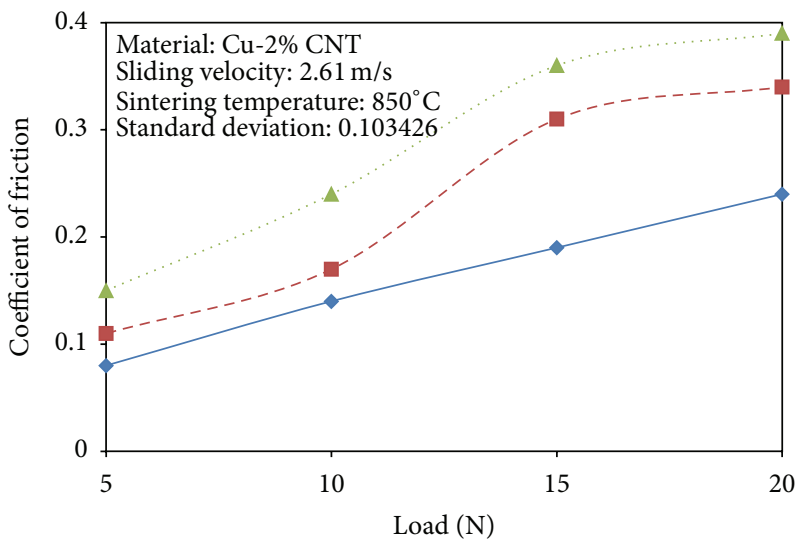

Sliding distance:

$\rightarrow 500 \mathrm{~m}$

- $-1000 \mathrm{~m}$

-.. $1500 \mathrm{~m}$

(d)

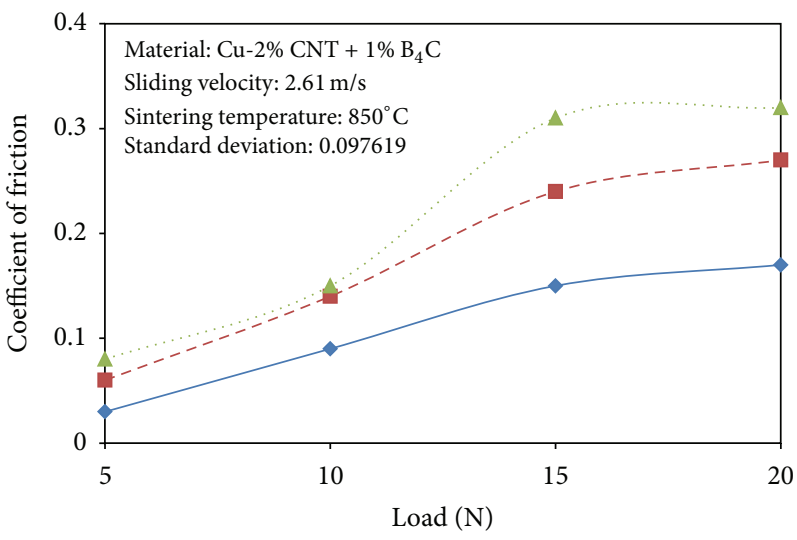

Sliding distance:

$\longrightarrow 500 \mathrm{~m}$

$-\square-1000 \mathrm{~m}$

- $1500 \mathrm{~m}$

(e)

FIGURE 11: Continued. 

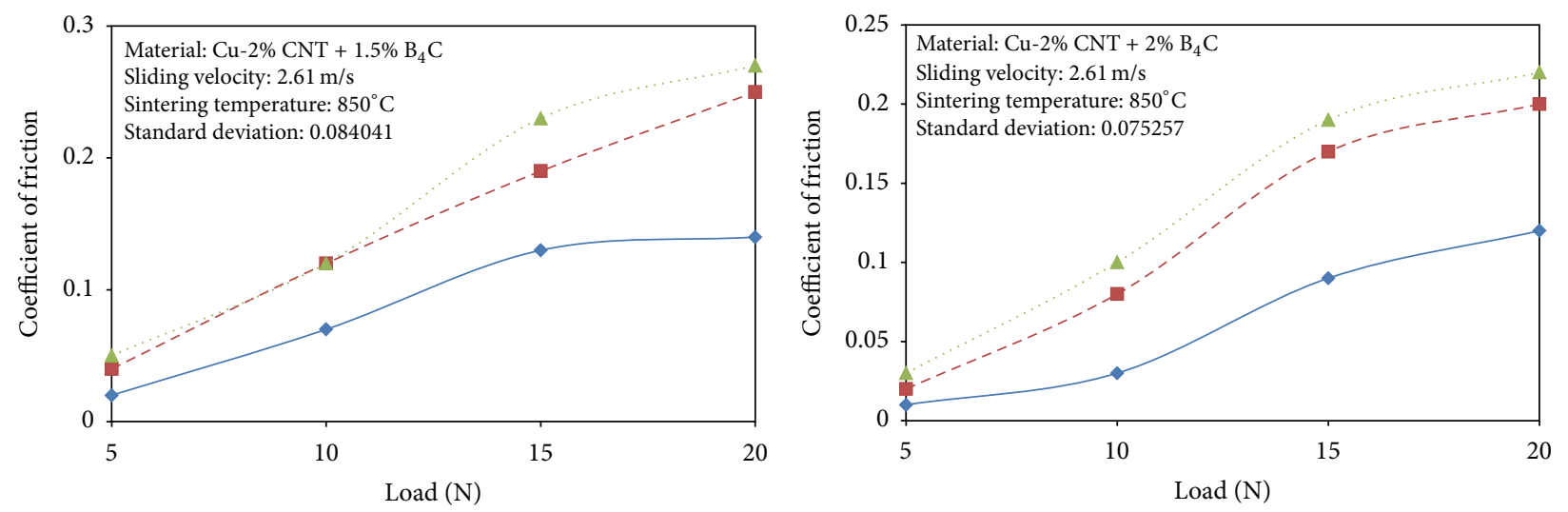

Sliding distance:

$$
\begin{aligned}
& \text { Sliding distance: } \\
& \rightarrow-500 \mathrm{~m} \\
& --1000 \mathrm{~m} \\
& -1500 \mathrm{~m}
\end{aligned}
$$

(g)

\begin{tabular}{|c|c|c|c|c|}
\hline Composites & Power law equation & $R^{2}$ & Polynomial equation & $R^{2}$ \\
\hline Pure copper & $y=1.8393 x^{0.0602}$ & 0.9892 & $y=-0.004 x^{2}+0.08 x+1.76$ & 1.0000 \\
\hline $\mathrm{Cu}-2 \mathrm{MWCNT}$ & $y=1.7393 x^{0.075}$ & 0.9994 & $y=-0.015 x^{2}+0.135 x+1.62$ & 1.0000 \\
\hline $\mathrm{Cu}-2 \mathrm{MWCNT}-0.5 \mathrm{~B}_{4} \mathrm{C}$ & $y=2.1775 x^{0.2161}$ & 0.9604 & $y=0.045 x^{2}+0.125 x+2.03$ & 1.0000 \\
\hline $\mathrm{Cu}-2 \mathrm{MWCNT}-1.0 \mathrm{~B}_{4} \mathrm{C}$ & $y=2.4554 x^{0.1971}$ & 0.9838 & $y=0.005 x^{2}+0.285 x+2.18$ & 1.0000 \\
\hline $\mathrm{Cu}-2 \mathrm{MWCNT}-1.5 \mathrm{~B}_{4} \mathrm{C}$ & $y=2.8191 x^{0.1886}$ & 0.9999 & $y=-0.065 x^{2}+0.585 x+2.3$ & 1.0000 \\
\hline $\mathrm{Cu}-2 \mathrm{MWCNT}-2.0 \mathrm{~B}_{4} \mathrm{C}$ & $y=3.1395 x^{0.2338}$ & 1.0000 & $y=-0.09 x^{2}+0.820 x+2.41$ & 1.0000 \\
\hline
\end{tabular}

FIGURE 11: (a-h) Variation of coefficient of friction with load.

TABLE 3: Curve fitting results of electrical resistivity versus varying temperature condition.

of nano- $\mathrm{B}_{4} \mathrm{C}$ particles changes the electronic structure of the composites and it affects the electrical resistivity.

3.4. Curve Fitting. A parabolic curve fitting technique was applied to relate the electrical resistivity of the copper hybrid composite preforms and the varying temperature conditions during the four-point probe testing. Curve fitting also known as regression analysis is used to find the "best fit" line or curve for a series of values. Using the curve fitting test technique, regression coefficient $\left(R^{2}\right)$ values of the composite preforms were determined from Figure 10. Table 3 lists the regression coefficient values for the power law and polynomial equations. The values were greater for the polynomial equation compared with those of the power law equation for all preforms. For all specimens, the regression coefficient of the polynomial equation is 1.00 , which indicates no difference between the experimental and predicted values. From Table 3, it is observed that the regression coefficient value increases with increasing amounts of nano- $\mathrm{B}_{4} \mathrm{C}$ particles. At the same time, the regression coefficient values for pure copper and 2 wt.\% reinforced copper exhibit a slightly higher value compared with those of preforms reinforced with $0.5 \mathrm{wt} . \%$ and 1.0 wt. $\%$ of $\mathrm{B}_{4} \mathrm{C}_{p}$ reinforced preforms. Among the various composite preforms, the power law and polynomial curve fitting equation were found to be the most efficient with regression coefficient values close to 1.00 for 2 wt. $\%$ MWCNT and $2 \mathrm{wt}$. $\%$ nano- $\mathrm{B}_{4} \mathrm{C}$-reinforced preforms.

3.5. Effect of the Coefficient of Friction on Load. Figures 11(a)11(h) show the coefficient of friction as a function of load at different sliding distances up to $100 \mathrm{~mm}$ for track radius and $2.61 \mathrm{~m} / \mathrm{s}$ for sliding velocity. Variations of the friction coefficient with normal load for the copper MWCNTs/nano$\mathrm{B}_{4} \mathrm{C}$ composites are shown in Figures 11(a)-11(c). The increasing trend of the coefficient of friction with increasing sliding distance is observed at all load levels. The coefficient of friction decreases with an increasing amount of secondary reinforcement $\left(\mathrm{B}_{4} \mathrm{C}\right.$ addition) in the copper matrix [16]. The coefficient of friction value is much smaller for $2 \mathrm{wt} . \%$ of MWCNT and nano- $\mathrm{B}_{4} \mathrm{C}$-reinforced copper preforms compared with that of the other sintered copper preforms. Figures $11(d)-11(h)$ show the variation of the coefficient of friction as a function of load at various sliding distances of $500 \mathrm{~m}$, $1000 \mathrm{~m}$, and $1500 \mathrm{~m}$. The coefficient of friction value appears to be smaller for $2 \mathrm{wt}$ \% of $\mathrm{B}_{4} \mathrm{C}$-reinforced copper preform at a $500 \mathrm{~m}$ sliding distance. During the wear test, the contact surfaces were heated due to metal-on-metal contact in the initial stage of sliding, during which the coefficient of friction was perceived to be higher but was relatively low in the steady state. It is further observed that initial and steady states are 


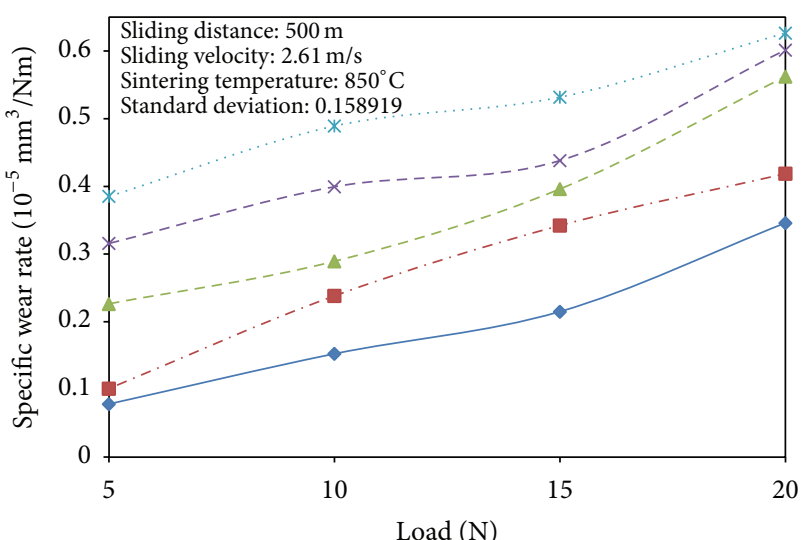

$\rightarrow \mathrm{Cu}+2 \% \mathrm{CNT}+2 \% \mathrm{~B}_{4} \mathrm{C} \quad-*-\mathrm{Cu}+2 \% \mathrm{CNT}+0.5 \% \mathrm{~B}_{4} \mathrm{C}$

$\rightarrow-\mathrm{Cu}+2 \% \mathrm{CNT}+1.5 \% \mathrm{~B}_{4} \mathrm{C} \quad \cdots * \cdot \mathrm{Cu}+2 \% \mathrm{CNT}$

$-\mathrm{Cu}+2 \% \mathrm{CNT}+1 \% \mathrm{~B}_{4} \mathrm{C}$

(a)

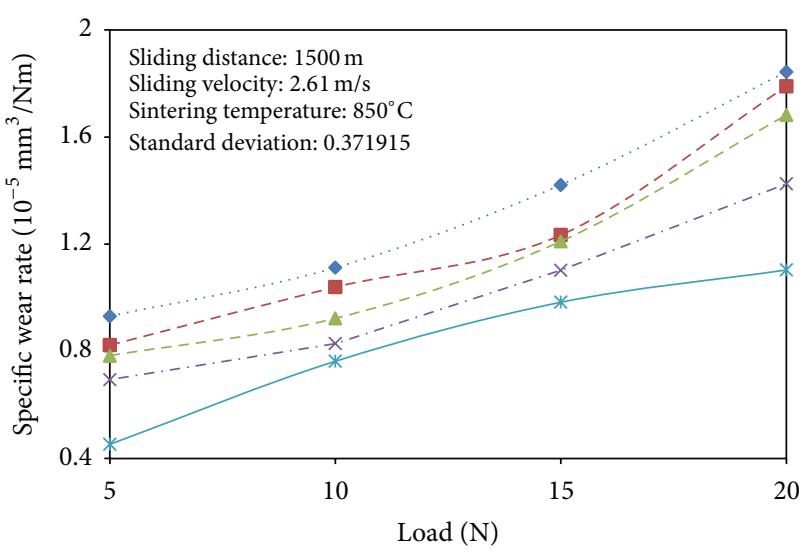

-. $\mathrm{Cu}-2 \% \mathrm{CNT}$

$-x-\mathrm{Cu}-2 \% \mathrm{CNT}+1.5 \% \mathrm{~B}_{4} \mathrm{C}$

- $\mathrm{Cu}-2 \% \mathrm{CNT}+0.5 \% \mathrm{~B}_{4} \mathrm{C}$

$-\mathrm{Cu}-2 \% \mathrm{CNT}+1 \% \mathrm{~B}_{4} \mathrm{C}$

(c)

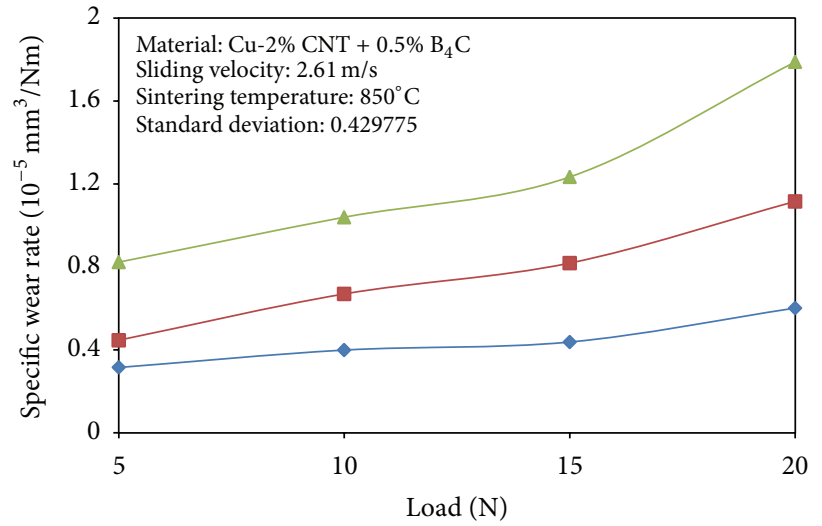

Sliding distance:

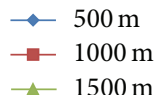

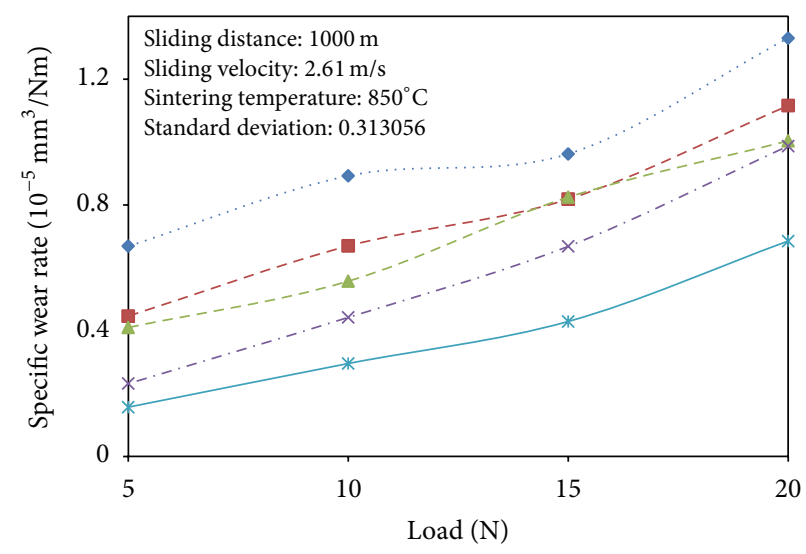

-. Cu-2\% CNT $-x-\mathrm{Cu}-2 \% \mathrm{CNT}+1.5 \% \mathrm{~B}_{4} \mathrm{C}$ - $\mathrm{Cu}-2 \% \mathrm{CNT}+0.5 \% \mathrm{~B}_{4} \mathrm{C} \quad$ * $\mathrm{Cu}-2 \% \mathrm{CNT}+2 \% \mathrm{~B}_{4} \mathrm{C}$

$-\mathrm{Cu}-2 \% \mathrm{CNT}+1 \% \mathrm{~B}_{4} \mathrm{C}$

(b)

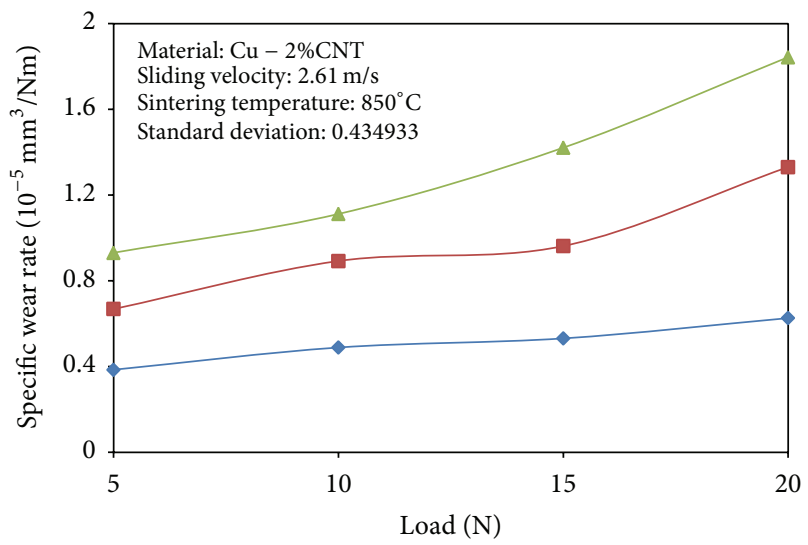

Sliding distance:

$\rightarrow 500 \mathrm{~m}$

$-1000 \mathrm{~m}$

$\rightarrow 1500 \mathrm{~m}$

(d)

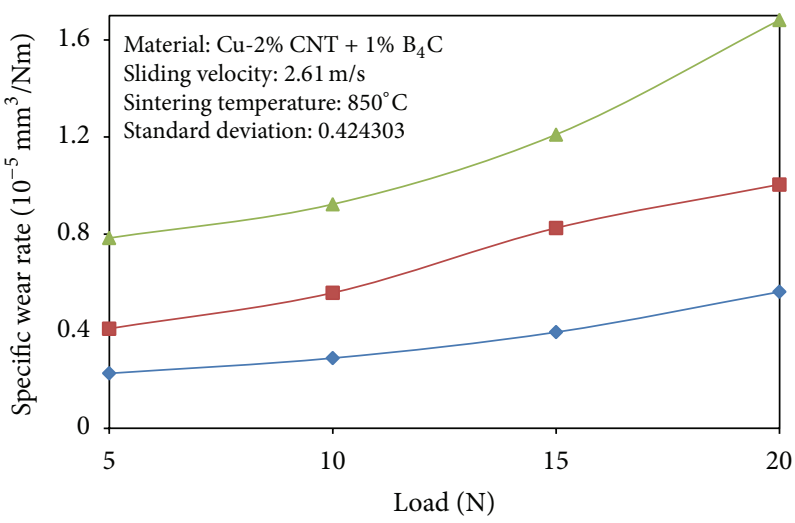

Sliding distance:

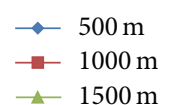

(e)

Figure 12: Continued. 


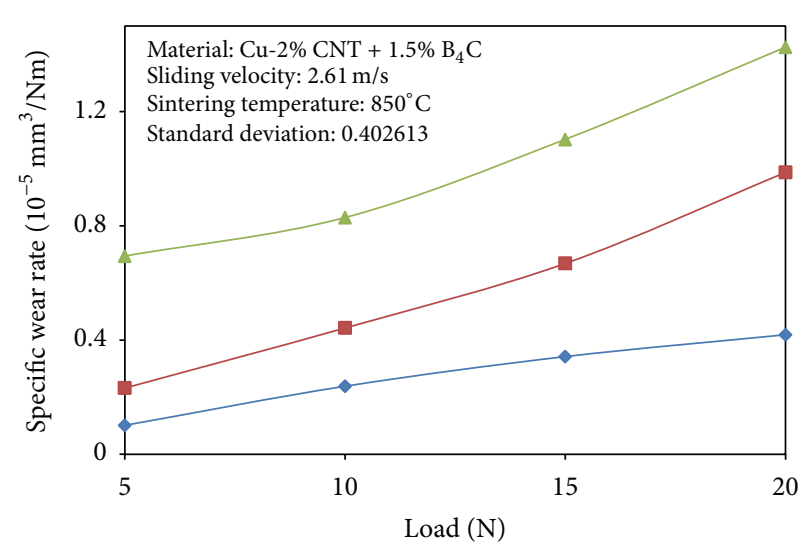

Sliding distance:
$\rightarrow 500 \mathrm{~m}$
$-1000 \mathrm{~m}$
$-1500 \mathrm{~m}$

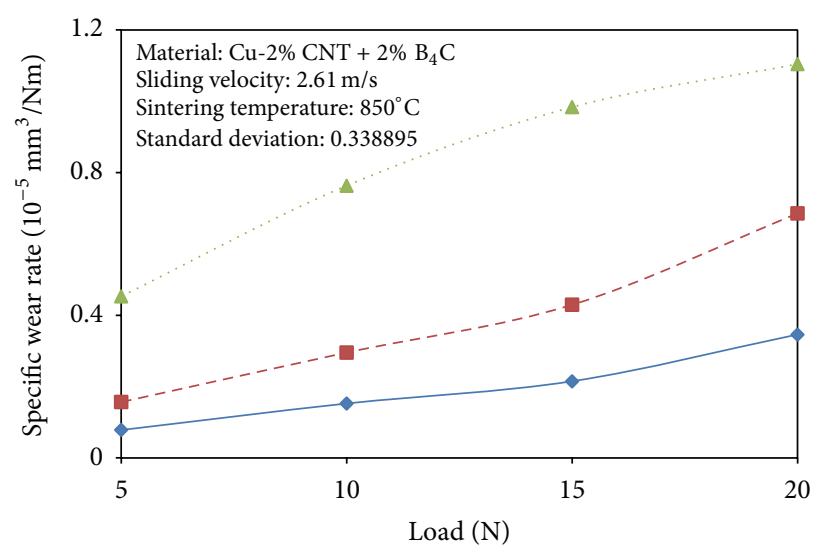

Sliding distance:
$\longrightarrow-500 \mathrm{~m}$
$-\square-1000 \mathrm{~m}$
$\therefore-1500 \mathrm{~m}$

(h)

(g)

FIGURE 12: (a-h) Effect of specific wear rate as a function of load.

influenced by the nature of the contact resulting from the initial metal-on-metal contact and the tribocontact separated by the carbon-rich layer $[20,22]$. In the primary state of sliding, the possibility of adhesion between the specimen and the countersurface is higher, which increases the coefficient of friction. The deep penetration of nanoreinforcements inside the asperities of the composite and counterface leads to a reduction in the friction coefficient.

Figures 11(a)-11(h) represent three different zones [32]. Zone 1 represents original specimen material in an undisturbed state. That is, this zone experiences elastic deformation and thermal cycling during tribocontact. However, the structure and properties of Zone 1 after the sliding test are identical to those prior to the test. The new structure and properties are developed at Zone 2 due to repetitive tribocontact and considerable plastic deformation occurs in ductile materials. Zone 2 becomes softer than the original material due to the material, environment, and contact conditions. The voids may develop within Zone 2 and cracks may nucleate this region. In many cases, the reorientation and disintegration of crystallites were observed in Zone 2. The microstructure refinement also occurred at Zone 2. However, there is no counterface and interaction with environment for Zone 2. The extent of deformation ranges from zero at Zone 1 to Zone 2 interfaces to maximum at the Zone 2-Zone 3 interface. Zone 3 is a tribolayer which differs compositionally as well as morphologically from the base material. Often Zone 3 appears to be homogeneous and very finely structured consisting of both specimen and counterface material. The subsurface damage increases when normal load increases and decreases with increase in the sliding speed [33]. Jahanmir [34] has studied the relationship between the tangential stress and wear particle formation mechanisms. It is concluded that when the tangential stress is low, wear occurs by surface deformation and material transfer to the harder component.
Under conditions of high tangential stress, wear occurs by delamination and material transfer.

The formation of a carbonaceous film between the specimen and the countersurface reduces the friction as well as the wear rate. Under normal load, MWCNTs from the composites are squeezed out to the contact surface, and hence, the coefficient of friction is decreased. The generation of loose wear debris on the counterface is due to the fragmentation of the copper matrix at higher loads, which tends to increase the friction coefficient. As expected, the variation of the coefficient of friction with load is marginally decreased for $2 \mathrm{wt} . \%$ $\mathrm{B}_{4} \mathrm{C}$-reinforced copper-MWCNT composites due to the even distribution of MWCNTs and $\mathrm{B}_{4} \mathrm{C}_{p}$ without agglomeration.

3.6. Specific Wear Rate. Figures 12(a)-12(h) illuminate the specific wear rate of various composite specimens as a function of load up to $100 \mathrm{~mm}$ for track radius and $2.61 \mathrm{~m} / \mathrm{s}$ for sliding velocity. Figures 12(a)-12(c) show the effect of the specific wear rate on copper $\mathrm{MWCNTs} / \mathrm{B}_{4} \mathrm{C}$-reinforced composite preforms as a function of normal load. Copper composites reinforced with 2 wt.\% MWCNTs and 2 wt.\% nano- $\mathrm{B}_{4} \mathrm{C}$ exhibited the lowest wear rate out of the entire range of loadings. As illustrated in Figure 12, the specific wear rate of copper composites increases with the increase in load and reaches a minimum of $0.0784 \times 10^{-5} \mathrm{~mm}^{3} / \mathrm{Nm}$ when the ratio of $\mathrm{B}_{4} \mathrm{C}$ is $2 \mathrm{wt} . \%$. The figure shows that when the sintering temperature and sliding velocity are held constant, the wear rate decreases as a function of the increase in amount of $\mathrm{B}_{4} \mathrm{C}$ in the copper matrix composites. The $\mathrm{B}_{4} \mathrm{C}$ particles are effective in enhancing the wear resistance of the copper hybrid composites. The increased wear resistance is attributed to the higher hardness of the secondary reinforcement $\left(B_{4} C\right)$, as is evident from Figure 9 [20]. It is well known that the hardness of the $\mathrm{B}_{4} \mathrm{C}$ particle is fairly high compared with that 
of the matrix (copper) and primary reinforcement (MWCNTs), and hence, the addition of $B_{4} C$ may enrich the hardness of composites as the wt.\% of $\mathrm{B}_{4} \mathrm{C}$ increases. Generally, the hardness of the composite specimen is inversely proportional to the wear rate of the material [26]. It is assumed that, with the addition of $\mathrm{B}_{4} \mathrm{C}$ content to the matrix, the fraction of $\mathrm{B}_{4} \mathrm{C}$ particles on the specimen surface increases, and accordingly, the contact between the pin and the disc decreases, thus subsidizing the reduction in the coefficient of friction compared with that of other specimens. Figures $12(\mathrm{~d})-12$ (h) show the specific wear rate of the fabricated hybrid nanocomposite specimens as a function of load at various sliding distances of $500 \mathrm{~m}, 1000 \mathrm{~m}$, and $1500 \mathrm{~m}$.

From the above discussion, we conclude that the nanoceramic addition had an obvious wear reduction effect under normal sliding conditions against the EN 31 steel disc along with $2 \%$ MWCNTs reinforced copper matrix which was beneficial in promoting the wear resistance of the prepared composites. From the above results, it was easier to conclude that the wear resistance of the tested specimens could be sorted into the following sequences: $\mathrm{Cu}-2 \mathrm{wt} . \%$ of MWCNT $<\mathrm{Cu}-2$ wt.\% of MWCNT- 0.5 wt. $\%$ of $\mathrm{B}_{4} \mathrm{C}<\mathrm{Cu}-2$ wt.\% of MWCNT-1 wt.\% of $\mathrm{B}_{4} \mathrm{C}<\mathrm{Cu}-2$ wt.\% of MWCNT-1.5 wt.\% of $\mathrm{B}_{4} \mathrm{C}<\mathrm{Cu}-2 \mathrm{wt} . \%$ of MWCNT-2 wt.\% of $\mathrm{B}_{4} \mathrm{C}$. At lower loads, the heat generated between the specimen and disc was quickly conducted away, whereas at higher loads, the conduction of heat was limited, which led to higher temperatures at the contact surface. As a result of the higher interface temperature, the mechanical strength of the composites is reduced, which leads to severe wear. It can be observed that the specific wear rates of the composites determined from the weight loss method vary from $0.0784 \times 10^{-5} \mathrm{~mm}^{3} / \mathrm{Nm}$ to $1.8432 \times 10^{-5} \mathrm{~mm}^{3} / \mathrm{Nm}$. This result clearly indicates that the wear resistance of the $2 \mathrm{wt} . \% \mathrm{~B}_{4} \mathrm{C}$-reinforced composite is superior to that of the other copper composites due to the addition of nanoceramic $\left(\mathrm{B}_{4} \mathrm{C}\right)$ particles to the copper matrix with uniform distribution.

3.7. Wear Mechanism. The wear test results for the composites reported in Figure 12 are supported by the SEM worn-surface micrographs of all fabricated composite grades. An analysis of the morphologies of the worn surfaces directs the existence of abrasion and delamination wear mechanisms in these composites. The analysis of the worn-surface morphology of the copper hybrid composites tested at $20 \mathrm{~N}$ load conditions is shown in Figures 13(a)-13(e). As noted previously (Figure 12(a)), in the case of the copper composite with $2 \mathrm{wt.} \%$ MWCNTs reinforcement, the dominant wear mechanisms are abrasion and delamination wear.

Figure 13(a) shows rough wear tracks with an uneven surface compared with that of other composite specimens and also that patches of harshly damaged regions and deep abrasion grooves were formed due to substantial plastic deformation. Figure 13(b) shows that rough wear track and also slight delamination layer occurred. It reveals that slight deformation occurred irrespective of the $0.5 \mathrm{wt} . \%$ of $\mathrm{B}_{4} \mathrm{C}$ particles when compared with $\mathrm{Cu}-2 \mathrm{wt} . \%$ composite. Figure 13(c) shows the worn surfaces of the Cu- 2 wt. $\%$ CNT- 1 wt. $\% \mathrm{~B}_{4} \mathrm{C}$ hybrid composites. Surface damage in the form of wear debris near to the contact surface was observed and also the prevention of direct metal contact between the two contact surfaces was reduced due to the fact that nano- $\mathrm{B}_{4} \mathrm{C}$ particles have smeared out from the composites and form a carbon layer between sliding surfaces. Figure 13(d) shows the worn surfaces of $\mathrm{Cu}-2$ wt.\% CNT-1.5 wt.\% $\mathrm{B}_{4} \mathrm{C}$. Due to increase in $\mathrm{B}_{4} \mathrm{C}$ particle on the surface of matrix, the plastic deformation of matrix can be repelled with the presence of $\mathrm{B}_{4} \mathrm{C}$ particles which act as an obstacle to the moment of dislocation which causes the more wear resistance than base material. The mild patches and tribolayer are noticed in Figure 13(d). Figure 13(e) shows a photo of the wear tracks after the addition of $\mathrm{B}_{4} \mathrm{C}_{p}$ to the copper matrix in which dominant wear mechanism has changed to mostly abrasion wear. The smeared carbon particles from the contact surface of the composites form a thin carbon-rich tribofilm at the interface region, which prevents direct metal contact between the specimens and the disc. Figures 13(e) and 13(f) show that the worn surface and EDS spectra of 2 wt.\% $\mathrm{B}_{4} \mathrm{C}$-reinforced composite are completely protected by a dark surface (carbon) layer that is smoother than that of the other composite specimens. Peak present at an energy value of $8.904 \mathrm{eV}$ is matching with the $\mathrm{K} \beta_{1}$ value of copper. Another peak present at $1.775 \mathrm{eV}$ is the $\mathrm{M} \alpha_{1}$ value of tungsten, which aroused due to the contamination during ball milling in a WC vial with WC balls. Several researchers [35-37] observed the formation of stable carbon-rich layers in the interface region, which act as a protective layer (tribolayer) that evenly distributes the load over the metal matrix composites. Because the nanoceramic particles $\left(\mathrm{B}_{4} \mathrm{C}\right)$ are much harder than the matrix $(\mathrm{Cu})$, higher wear resistance can be obtained [38,39].

Moreover, with the increased addition of reinforcements, the worn surfaces of the copper composites become smoother. The $\mathrm{B}_{4} \mathrm{C}_{p}$ and MWCNTs particles can act as obstacles and can protect the copper matrix from plastic deformation and destructive action, thus leading to less microploughing along the sliding direction and higher wear resistance of the composites. As the load/sliding distance increases, the amount of wear debris and the size of the delamination increase for the composites. However, the depth and width of the ploughing observed in $2 \mathrm{wt} . \%$ reinforced $\mathrm{B}_{4} \mathrm{C}$ specimens are shallower than those of other specimens due to the additional formation of hard asperities on the contact surface of the pins, which restricts the flow of materials.

3.8. Wear Debris Analysis. Figures 14(b)-14(f) show the results of the wear debris morphology of Cu-MWCNTs$\mathrm{B}_{4} \mathrm{C}_{p}$ composite specimens under a normal load of $20 \mathrm{~N}$ examined via SEM. Figure 14(a) shows a photograph of the collected wear debris particles of the copper composite specimens after the wear test. All of the wear debris particles of the copper composite specimens appear black coloured, which indicates the presence of carbon. The copper debris was covered with a dominant black colour, which confirms the formation of carbon-rich tribolayer at the interface region. Both flake-like and particle-like morphologies are observed in the copper hybrid composites. The wear debris originates from the particles of plastically deformed surface layers of the nanohybrid specimens. This result shows that the 


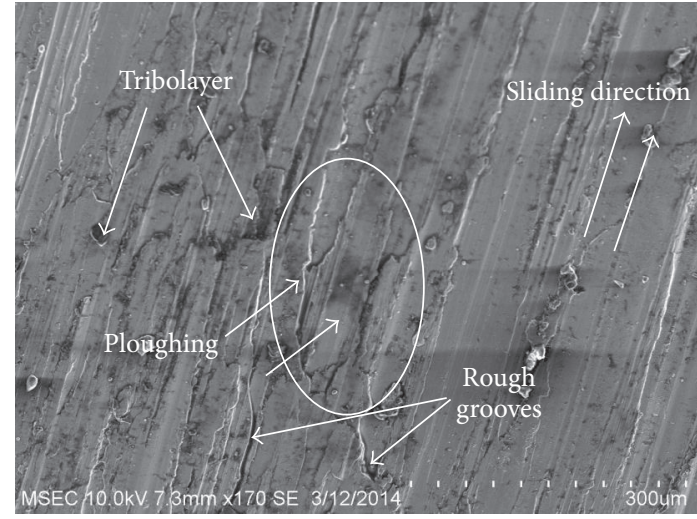

(a)

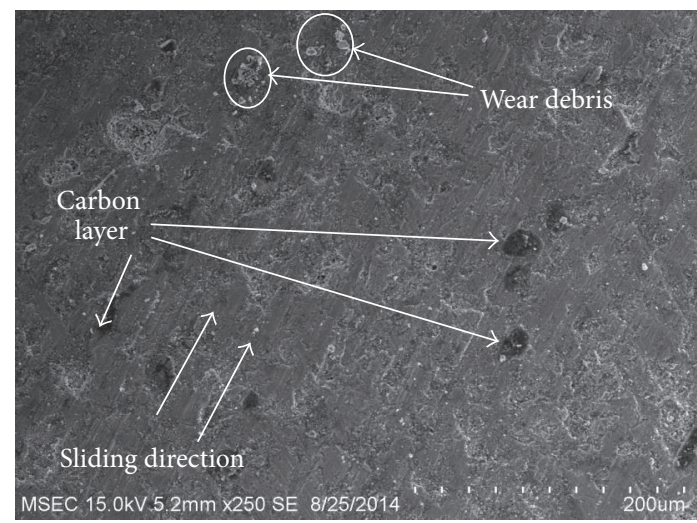

(c)

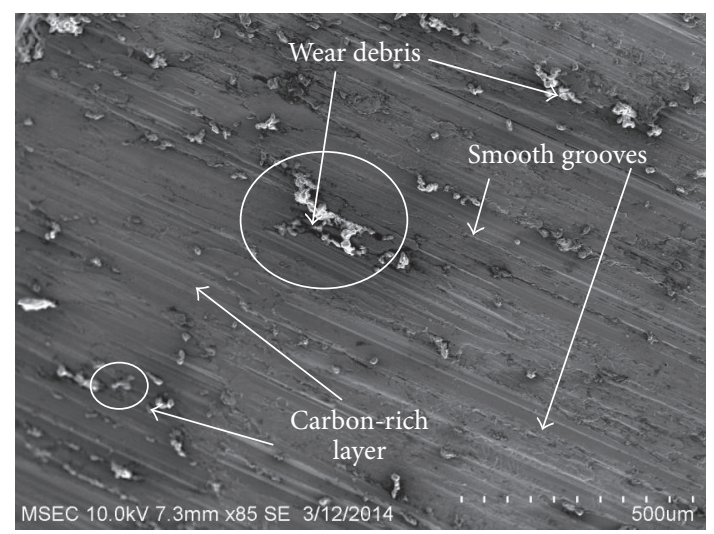

(e)

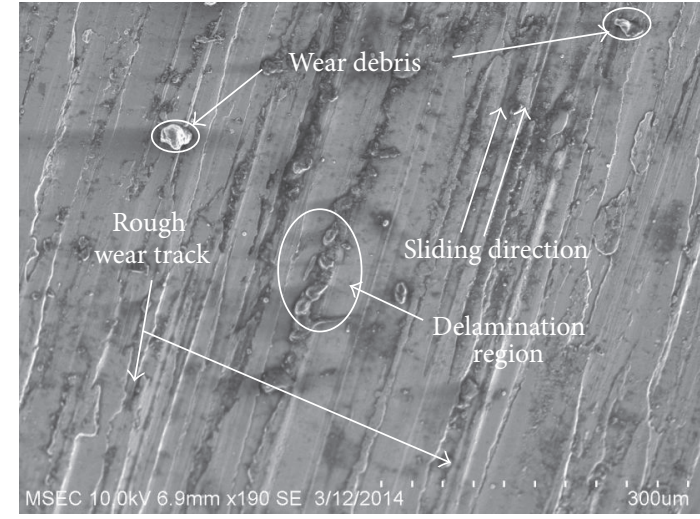

(b)

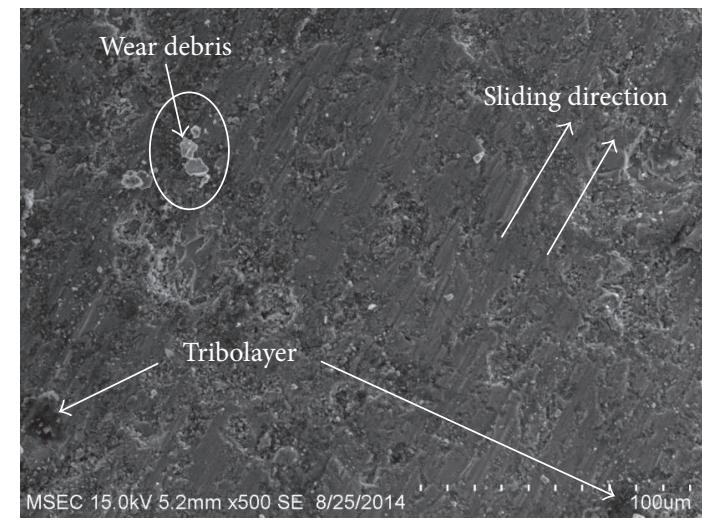

(d)

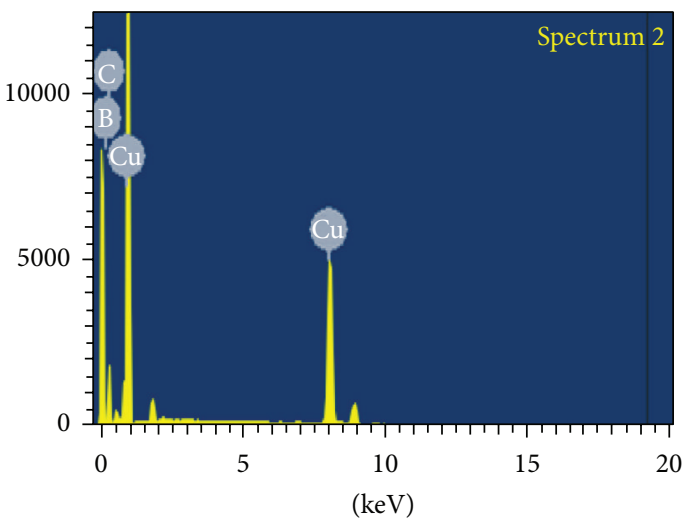

Full scale 12405 cts cursor: 19.255 ( 1 cts)

(f)

FIGURE 13: (a-e) Worn surface analysis of composites at $20 \mathrm{~N}$ loads: (a) $\mathrm{Cu}-2 \mathrm{MWCNT}$, (b) $\mathrm{Cu}-2 \mathrm{MWCNT}-0.5 \mathrm{~B}_{4} \mathrm{C},(\mathrm{c}) \mathrm{Cu}-2 \mathrm{MWCNT}-1.0 \mathrm{~B}_{4} \mathrm{C}$, (d) $\mathrm{Cu}-2 \mathrm{MWCNT}-1.5 \mathrm{~B}_{4} \mathrm{C}$, (e) $\mathrm{Cu}-2 \mathrm{MWCNT}-2.0 \mathrm{~B}_{4} \mathrm{C}$, and (f) EDAX for $\mathrm{Cu}-2 \mathrm{MWCNT}-2.0 \mathrm{~B}_{4} \mathrm{C}$.

flake-like debris of the copper composites could be generated via a delamination mechanism.

3.9. Role of Reinforcements. From the previous results of the mechanical, electrical, and wear properties of copper performs, significant improvement in hardness, wear resistance, and electrical resistivity is observed with the addition of reinforcements.
Generally, MWCNTs added into the copper matrix as a contributing reinforcement phase together with nano- $\mathrm{B}_{4} \mathrm{C}_{p}$ produce notably high value of hardness due to the unique combination of high elastic modulus and high strain to failure that enhances the hardness of the composites. The addition of primary reinforcements reduces the coefficient of friction and the wear rates of the composites via encapsulation of the MWCNTs with the copper matrix, which increases 


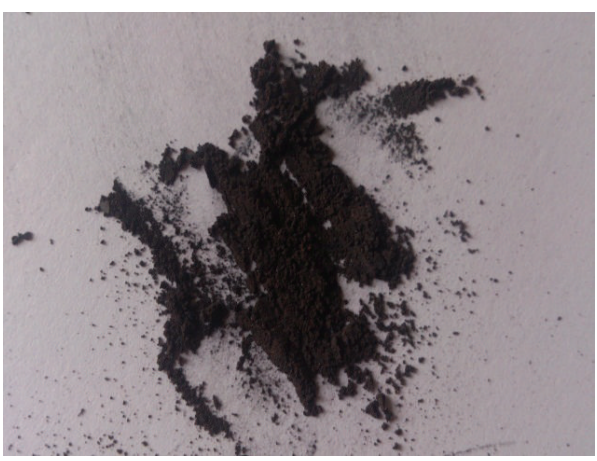

(a)

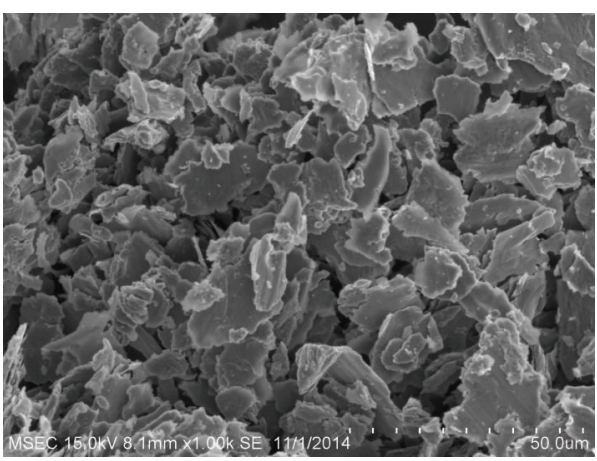

(c)

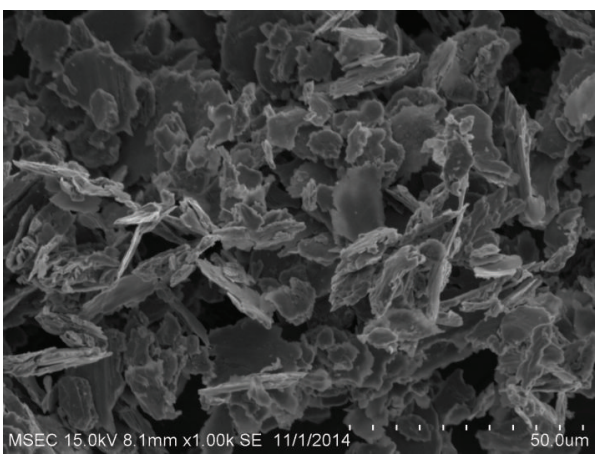

(e)

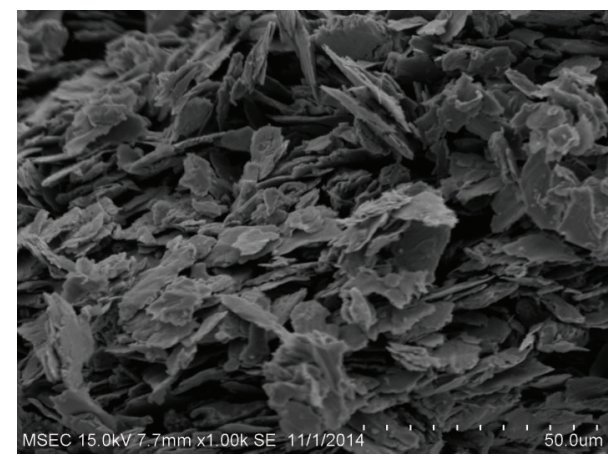

(b)

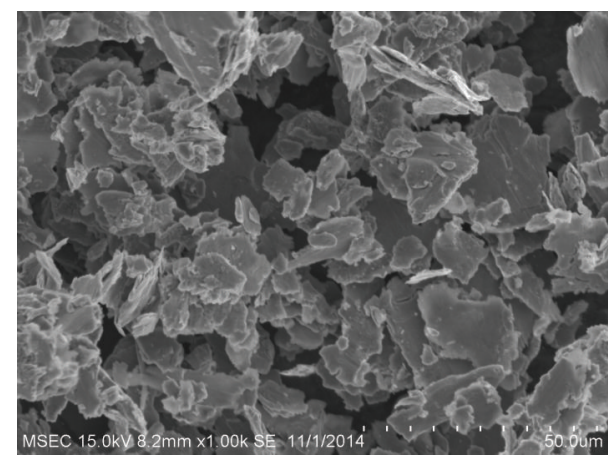

(d)

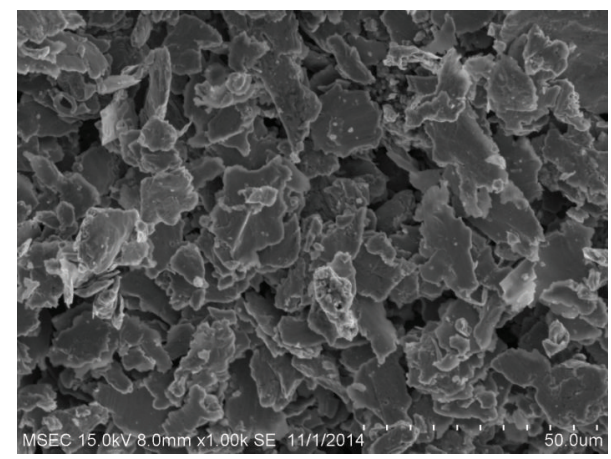

(f)

Figure 14: (a) Photograph of the collected wear debris particles, (b-e) worn surface analysis of composite specimens at $20 \mathrm{~N}$ loads: (a) Cu2MWCNT, (b) Cu-2MWCNT-0.5B $\mathrm{B}_{4} \mathrm{C}$, (c) Cu-2MWCNT-1.0B $\mathrm{B}_{4} \mathrm{C}$, (d) Cu-2MWCNT-1.5B $\mathrm{B}_{4} \mathrm{C}$, and (e) Cu-2MWCNT-2.0B $\mathrm{B}_{4} \mathrm{C}$.

the interfacial bond strength. The superior wear behaviour of MWCNT-reinforced hybrid composites is attributed to the high cohesive strength of the reinforcement with the copper matrix and reduced deformation of the composite specimens during wear testing. The formation of a carbonaceous film at the interface region with the addition of MWCNTs to the matrix (copper) produces a self-lubrication effect that avoids direct metal-on-metal contact and enhances the wear resistance of the hybrid composites. The electrical resistivity of MWCNTs is less than that of the pure copper matrix, and the composite acts as an intrinsic conductive material. The electrical resistivity of copper hybrid composites incorporated with 2 wt.\% of MWCNTs is lower than that of the pure copper specimen.
The secondary reinforcement of nano- $\mathrm{B}_{4} \mathrm{C}$ (hard ceramic) has a greater hardness value, third behind that of diamonds and cubic boron nitride. The structural strength of this material is also high due to the semicrystalline structure of $\mathrm{B}_{4} \mathrm{C}$. The electrical resistivity of $\mathrm{B}_{4} \mathrm{C}$ incorporated into the copper matrix was found to be significantly less than those of pure copper and MWCNTs. Thus, milled nano- $\mathrm{B}_{4} \mathrm{C}$ reinforced $\mathrm{Cu}-\mathrm{MWCNT}$ composites provide outstanding wear resistance.

\section{Conclusions}

This work investigated the wear resistance and electrical and mechanical behaviours of copper hybrid composites 
fabricated using the powder metallurgy method. The overall results for $\mathrm{P} / \mathrm{M}$-prepared copper nanohybrid composites can be summarized as follows:

(i) The presence of copper, MWCNTs, and $\mathrm{B}_{4} \mathrm{C}$ was confirmed using the XRD analysis technique.

(ii) Scanning electron micrographs of the composite powders showed a homogeneous distribution of both primary (MWCNTs) and secondary $\left(\mathrm{B}_{4} \mathrm{C}\right)$ reinforcements in the matrix.

(iii) Among the five different composites, wear resistance was found to be superior for a $2 \mathrm{wt} \% \mathrm{~B}_{4} \mathrm{C}$-reinforced copper composite.

(iv) The superior wear resistance of the composite is attributed to the refinement of grain size (reinforcements) and filling of pores, which enhances the bonding strength between the matrix and the reinforcements.

(v) Increasing the amount of nano- $\mathrm{B}_{4} \mathrm{C}$ particles led to a reduced coefficient of friction.

(vi) Nano- $\mathrm{B}_{4} \mathrm{C}$ particles added to the matrix material increased the electrical resistivity (decreased conductivity) of the hybrid composites.

(vii) We concluded that even distribution of MWCNT and $\mathrm{B}_{4} \mathrm{C}$ coupled with good relative density enhances the hardness and wear resistance and decreases the porosity of composites.

\section{Additional Points}

The highlights of the current study are as follows:

(i) Wear test was conducted on $\mathrm{Cu}-\mathrm{MWCNT}-\mathrm{B}_{4} \mathrm{C}$ composites.

(ii) Composites are fabricated with less porosity.

(iii) Wear resistance was enriched due to the addition of hard reinforcements.

(iv) Hardness of the composites was improved without deteriorating its conductivity.

(v) The electrical conductivity is just weakly affected by the addition of $\mathrm{B}_{4} \mathrm{C}_{p}$.

\section{Competing Interests}

The authors declare that they have no competing interests.

\section{References}

[1] N. Selvakumar and S. C. Vettivel, "Thermal, electrical and wear behavior of sintered $\mathrm{Cu}-\mathrm{W}$ nanocomposite," Materials and Design, vol. 46, pp. 16-25, 2013.

[2] L. Zhang, X. B. He, X. H. Qu, B. H. Duan, X. Lu, and M. L. Qin, "Dry sliding wear properties of high volume fraction $\mathrm{SiC}_{p} / \mathrm{Cu}$ composites produced by pressureless infiltration," Wear, vol. 265, no. 11-12, pp. 1848-1856, 2008.
[3] C. S. Ramesh, R. Noor Ahmed, M. A. Mujeebu, and M. Z. Abdullah, "Development and performance analysis of novel cast copper-SiC-Gr hybrid composites," Materials and Design, vol. 30, no. 6, pp. 1957-1965, 2009.

[4] K. Rajkumar and S. Aravindan, "Tribological performance of microwave sintered copper-TiC-graphite hybrid composites," Tribology International, vol. 44, no. 4, pp. 347-358, 2011.

[5] S. C. Vettivel, N. Selvakumar, and P. Vijay Ponraj, "Mechanical behaviour of sintered $\mathrm{Cu}-5 \% \mathrm{~W}$ nano powder composite," Procedia Engineering, vol. 38, pp. 2874-2880, 2012.

[6] C. Kim, B. Lim, B. Kim et al., "Strengthening of copper matrix composites by nickel-coated single-walled carbon nanotube reinforcements," Synthetic Metals, vol. 159, no. 5-6, pp. 424-429, 2009.

[7] A. K. Shukla, N. Nayan, S. V. S. N. Murty et al., "Processing copper-carbon nanotube composite powders by high energy milling," Materials Characterization, vol. 84, pp. 58-66, 2013.

[8] A. Maqbool, M. A. Hussain, F. A. Khalid, N. Bakhsh, A. Hussain, and M. H. Kim, "Mechanical characterization of copper coated carbon nanotubes reinforced aluminum matrix composites," Materials Characterization, vol. 86, pp. 39-48, 2013.

[9] S. M. Uddin, T. Mahmud, C. Wolf et al., "Effect of size and shape of metal particles to improve hardness and electrical properties of carbon nanotube reinforced copper and copper alloy composites," Composites Science and Technology, vol. 70, no. 16, pp. 2253-2257, 2010.

[10] G. Praveennath Koppad, H. R. Aniruddha Rama, C. S. Ramesh, K. T. Kashyap, and G. Ravikiran, "On thermal and electrical properties of multiwalled carbon nanotubes/copper matrix nanocomposites," Journal of Alloys and Compounds, vol. 580, pp. 527-532, 2013.

[11] C. L. Xu, B. Q. Wei, R. Z. Ma, J. Liang, X. K. Ma, and D. H. $\mathrm{Wu}$, "Fabrication of aluminum-carbon nanotube composites and their electrical properties," Carbon, vol. 37, no. 5, pp. 855858, 1999.

[12] L. X. Pang, K. N. Sun, S. Ren, C. Sun, and J. Q. Bi, "Microstructure, hardness, and bending strength of carbon nanotube-iron aluminide composites," Journal of Composite Materials, vol. 41, no. 16, pp. 2025-2031, 2007.

[13] K. T. Kim, S. I. Cha, S. H. Hong, and S. H. Hong, "Microstructures and tensile behavior of carbon nanotube reinforced $\mathrm{Cu}$ matrix nanocomposites," Materials Science and Engineering A, vol. 430, no. 1-2, pp. 27-33, 2006.

[14] S. R. Bakshi, V. Singh, S. Seal, and A. Agarwal, "Aluminum composite reinforced with multiwalled carbon nanotubes from plasma spraying of spray dried powders," Surface and Coatings Technology, vol. 203, no. 10-11, pp. 1544-1554, 2009.

[15] T. Laha, Y. Liu, and A. Agarwal, "Carbon nanotube reinforced aluminum nanocomposite via plasma and high velocity oxyfuel spray forming," Journal of Nanoscience and Nanotechnology, vol. 7, no. 2, pp. 515-524, 2007.

[16] P. Ravindran, K. Manisekar, P. Narayanasamy, N. Selvakumar, and R. Narayanasamy, "Application of factorial techniques to study the wear of Al hybrid composites with graphite addition," Materials \& Design, vol. 39, pp. 42-54, 2012.

[17] Y. Q. Wang, A. M. Afsar, J. H. Jang, K. S. Han, and J. I. Song, "Room temperature dry and lubricant wear behaviors of $\mathrm{Al}_{2} \mathrm{O}_{3 f} / \mathrm{SiC}_{p} / \mathrm{Al}$ hybrid metal matrix composites," Wear, vol. 268, no. 7-8, pp. 863-870, 2010.

[18] N. B. Dhokey and R. K. Paretkar, "Study of wear mechanisms in copper-based $\mathrm{SiC}_{p}$ (20\% by volume) reinforced composite," Wear, vol. 265, no. 1-2, pp. 117-133, 2008. 
[19] N. Selvakumar, A. P. Mohan Raj, and R. Narayanasamy, "Experimental investigation on workability and strain hardening behaviour of $\mathrm{Fe}-\mathrm{C}-0.5 \mathrm{Mn}$ sintered composites," Materials \& Design, vol. 41, pp. 349-357, 2012.

[20] F. Bedir, "Characteristic properties of Al-Cu-SiCp and Al$\mathrm{Cu}-\mathrm{B} 4 \mathrm{Cp}$ composites produced by hot pressing method under nitrogen atmosphere," Materials \& Design, vol. 28, no. 4, pp. 1238-1244, 2007.

[21] P. Ravindran, K. Manisekar, S. Vinoth Kumar, and P. Rathika, "Investigation of microstructure and mechanical properties of aluminum hybrid nano-composites with the additions of solid lubricant," Materials \& Design, vol. 51, pp. 448-456, 2013.

[22] K. Rajkumar and S. Aravindan, "Tribological studies on microwave sintered copper-carbon nanotube composites," Wear, vol. 270, no. 9-10, pp. 613-621, 2011.

[23] A. M. K. Esawi, K. Morsi, A. Sayed, M. Taher, and S. Lanka, "The influence of carbon nanotube (CNT) morphology and diameter on the processing and properties of CNT-reinforced aluminium composites," Composites Part A: Applied Science and Manufacturing, vol. 42, no. 3, pp. 234-243, 2011.

[24] D. Jeyasimman, K. Sivaprasad, S. Sivasankaran, and R. Narayanasamy, "Fabrication and consolidation behavior of Al 6061 nanocomposite powders reinforced by multi-walled carbon nanotubes," Powder Technology, vol. 258, pp. 189-197, 2014.

[25] H. Xu, X. Cheng, J. Zhong et al., "Characterization of multiwalled carbon nanotubes dispersing in water and association with biological effects," Journal of Nanomaterials, vol. 2011, Article ID 938491, 12 pages, 2011.

[26] S. C. Vettivel, N. Selvakumar, N. Leema, and A. Haiter Lenin, "Electrical resistivity, wear map and modeling of extruded tungsten reinforced copper composite," Materials \& Design, vol. 56, pp. 791-806, 2014.

[27] S. Suresh, N. Shenbaga Vinayaga Moorthi, S. C. Vettivel, and N. Selvakumar, "Mechanical behavior and wear prediction of stir cast $\mathrm{Al}-\mathrm{TiB}_{2}$ composites using response surface methodology," Materials \& Design, vol. 59, pp. 383-396, 2014.

[28] S. Balamurugan, K. S. Asha Mini, T. S. Gokul Raja, and P. Parthiban, "Mechano-thermal synthesis and characterization of $\mathrm{BaMnO}_{3}$ nano-needles," Journal of Nanoscience and Nanotechnology, vol. 15, no. 8, pp. 5978-5986, 2015.

[29] Y. A. Sorkhe, H. Aghajani, and A. Taghizadeh Tabrizi, "Mechanical alloying and sintering of nanostructured $\mathrm{TiO}_{2}$ reinforced copper composite and its characterization," Materials \& Design, vol. 58, pp. 168-174, 2014.

[30] F. Monteverde, A. Bellosi, and S. Guicciardi, "Processing and properties of zirconium diboride-based composites," Journal of the European Ceramic Society, vol. 22, no. 3, pp. 279-288, 2002.

[31] H. Kaya, "Dependence of electrical resistivity on temperature and composition of Al-Cu alloys," Materials Research Innovations, vol. 16, no. 3, pp. 224-229, 2012.

[32] S. L. Rice, H. Nowotny, and S. F. Wayne, "A survey of the development of subsurface zones in the wear of materials," Trans Tech Publications, vol. 33, pp. 77-100, 1991.

[33] K. M. Jasim, "Nature of subsurface damage in Al-22 wt.\%Si alloys sliding dry on steel discs at high sliding speeds," Wear, vol. 98, pp. 183-197, 1984.

[34] S. Jahanmir, "The relationship of tangential stress to wear particle formation mechanisms," Wear, vol. 103, no. 3, pp. 233252, 1985.
[35] M. R. Rosenberger, E. Forlerer, and C. E. Schvezov, "Wear behavior of AA1060 reinforced with alumina under different loads," Wear, vol. 266, no. 1-2, pp. 356-359, 2009.

[36] R. L. Deuis, C. Subramanian, and J. M. Yellup, "Dry sliding wear of aluminium composites-a review," Composites Science and Technology, vol. 57, no. 4, pp. 415-435, 1997.

[37] A. E. Jiménez, M. D. Bermúdez, J. Cintas, and E. J. Herrera, "Dry wear of $\mathrm{NiAl}_{3}$-reinforced mechanically alloyed aluminium with different microstructure," Wear, vol. 266, no. 1-2, pp. 255-265, 2009.

[38] E. M. Sharifi and F. Karimzadeh, "Wear behavior of aluminum matrix hybrid nanocomposites fabricated by powder metallurgy," Wear, vol. 271, no. 7-8, pp. 1072-1079, 2011.

[39] B. Selvam, P. Marimuthu, R. Narayanasamy et al., "Dry sliding wear behaviour of zinc oxide reinforced magnesium matrix nano-composites," Materials \& Design, vol. 58, pp. 475-481, 2014. 

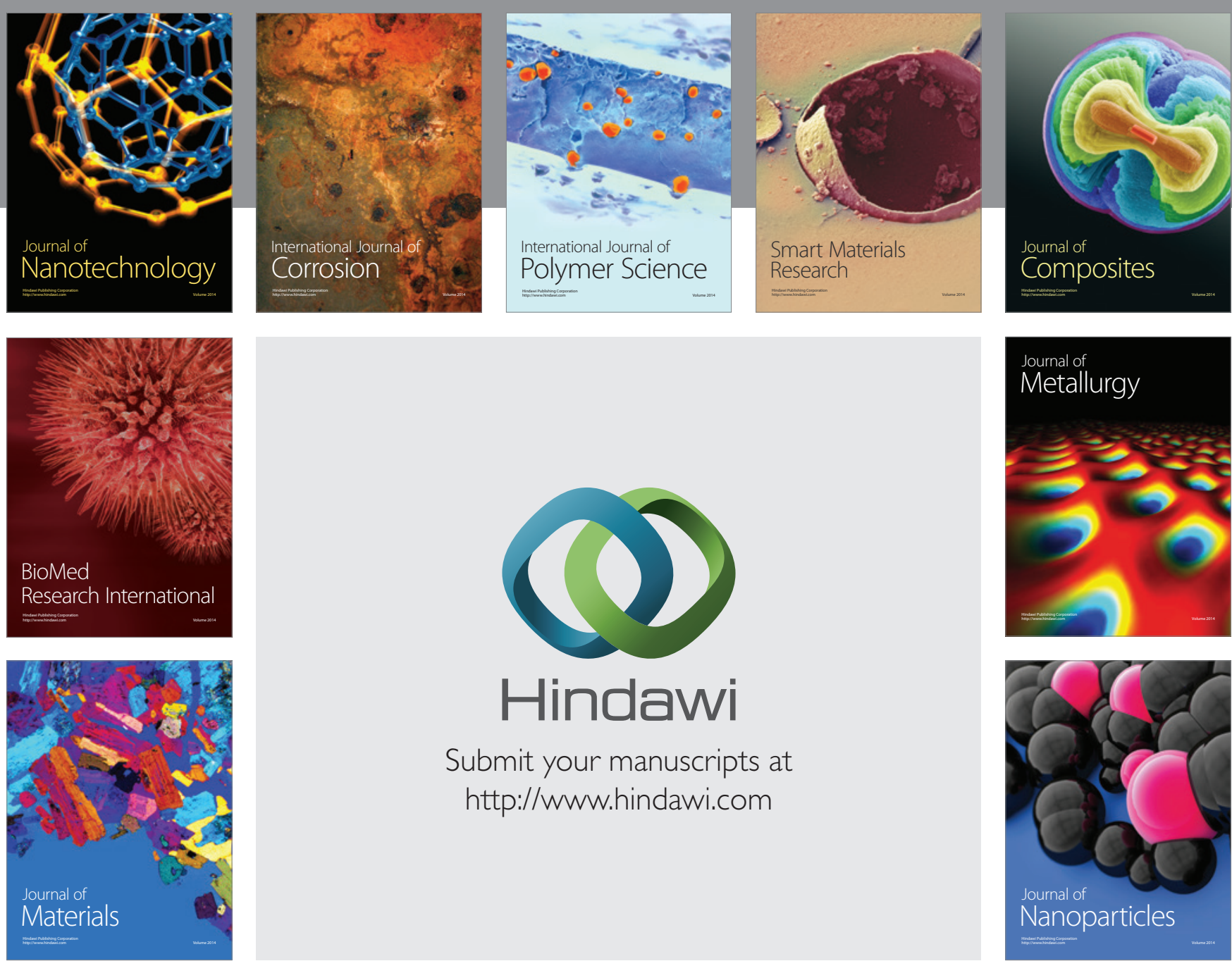

\section{Hindawi}

Submit your manuscripts at

http://www.hindawi.com

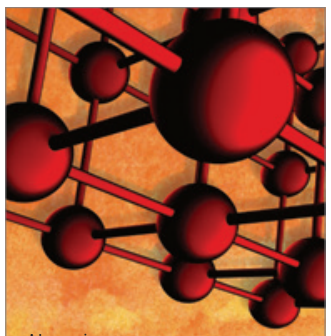

Materials Science and Engineering
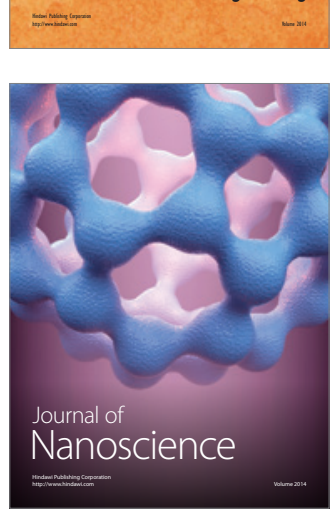
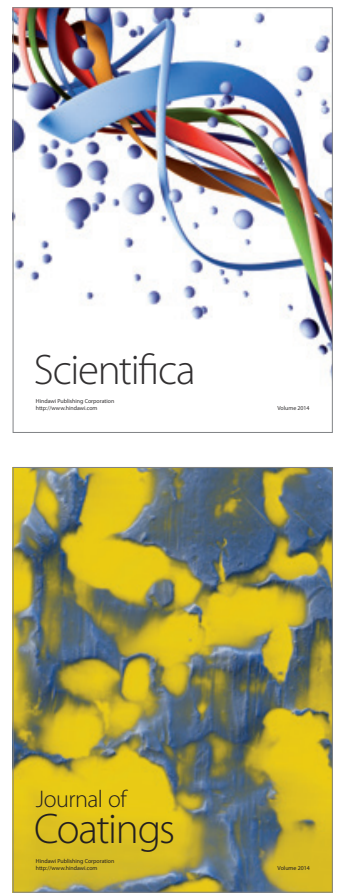
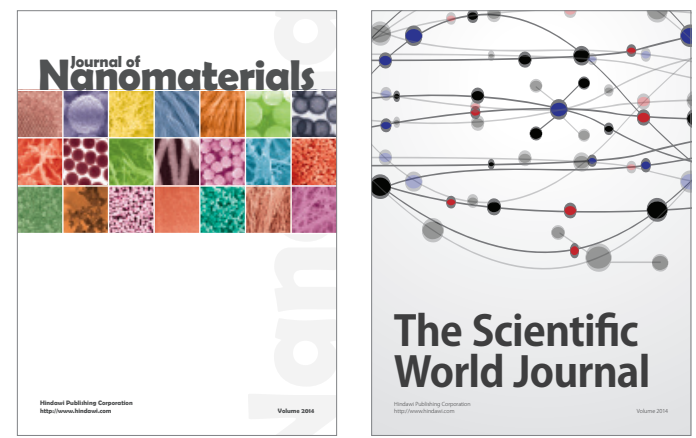

The Scientific World Journal
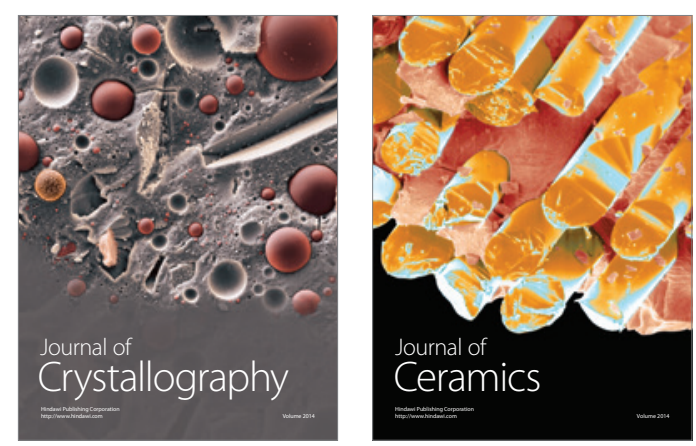
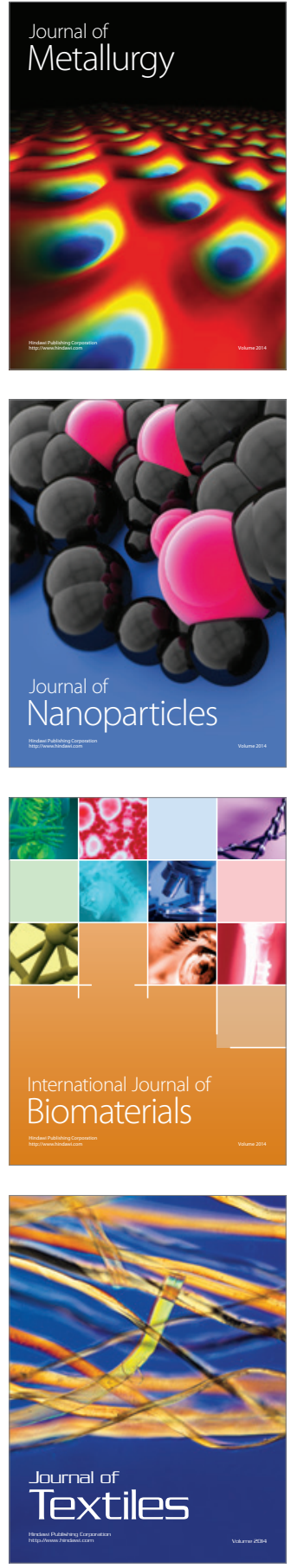